\title{
Changes in fertility plans during the COVID-19 pandemic in Italy: the role of occupation and income vulnerability
}

\author{
Bruno Arpino ${ }^{1}$, Francesca Luppi ${ }^{2} \&$ Alessandro Rosina ${ }^{3}$
}

\begin{abstract}
The health and economic crisis generated by the COVID-19 pandemic is unprecedented in recent human history. We investigate the role of objective and subjective indicators of economic uncertainty due to the COVID-19 crisis in young Italians' fertility plans during the year 2020. We use unique repeated cross-sectional data, collected at different time points during the pandemic (March and October/November 2020) together with pre-COVID data (2016). The data offer a standard fertility intention question pre- and during-COVID, and also a direct question on whether pre-COVID fertility plans have been confirmed, postponed or abandoned. We find that individuals with more vulnerable occupations show a lower probability of definitely intending to have a(nother) child in the short-term and a higher probability of having abandoned their pre-COVID fertility plan in March 2020, while in October 2020 changes in fertility plans did not vary by occupation. Instead, those who suffered from a negative income shock and those with negative expectations on their future income and occupation are more likely to abandon their pre-pandemic fertility plan compared to their better off counterparts, and these differences hold both in March and October. Overall, economic uncertainty generated by the pandemic seems to have similarly affected men and women's fertility intentions. Our findings point to the fact that the unequal economic consequences of the pandemic also produced and will produce heterogeneous effects on fertility intentions.
\end{abstract}

Keywords: covid-19, sars-cov-2, coronavirus, fertility plans, economic uncertainty, Italy

1 University of Florence, Department of Statistics, Computer Science, Applications, Florence (Italy): bruno.arpino@unifi.it

2 Università Cattolica del Sacro Cuore, Department of Statistics, Milan (Italy): francesca.luppi1@unicatt.it 3 Università Cattolica del Sacro Cuore, Department of Statistics, Milan (Italy): alessandro.rosina@unicatt.it 


\section{Introduction}

The COVID-19 crisis started as a health emergency in China at the end of 2019 and rapidly turned into a health pandemic and a global economic recession. The direct effects of the pandemic on mortality and morbidity have been widely studied (e.g., Drefahl et al. 2020, Nasiri et al. 2020). However, the COVID-19 pandemic likely had and will have broader demographic consequences.

In particular, since the very beginning of the pandemic, demographers have been debating about its possible consequences on fertility. The characteristics of the COVID-19 pandemic make it unprecedented in recent human history, but previous crises may help predicting the impact on fertility intentions and behaviours. When health and economic crises occur, the subsequent shocks and perceived uncertainty about the future produce major impacts on individual's life plans, especially those implying a considerable long-term investment, such as having a child. It is well grounded in the literature that fertility negatively responds to public health emergencies (e.g., Kearney and Levine 2020, Marteleto et al. 2020, Trinitapoli and Yeatman 2011) and economic crises (e.g., Sobotka et al. 2011, Vrachnis et al. 2014). Therefore, it is expected that economic and social changes derived by the pandemic will impact negatively on fertility, at least in high-income countries, both in the short and in the long term (Aassve et al. 2020).

Studies on health crises show evidence of strong drops in births during and after great epidemics (Stone 2020), such as the 1918-19 Spanish flu worldwide (Chandra and Yu 2015a, 2015b, Donaldson and Keniston 2014, Chandra et al. 2018) and the Zika epidemic in South America (Marteleto et al. 2020). Despite the 1918 and the 2020 pandemics share some similar patterns, differently from the Spanish flu, which strongly hit the young population, the COVID-19 pandemic, up to now, has increased mortality especially among older people (Ho et al., 2020). This means that the health dimension of the COVID-19 crisis may not be directly responsible for a revision of preCOVID fertility intentions, while the subsequent economic recession may produce such an effect.

As for previous economic crises, there is a wide literature on the effects of objective and subjective financial factors on fertility intentions and behaviours, both at the micro and the macro level (e.g., Sobotka et al. 2011, Goldstein et al. 2013, Matysiak et al. 2021, Dupray and Pailhé 2018, Pailhé and Solaz 2012, Palumbo and Sironi 2016, Modena and Sabatini 2012, Testa and Basten 2014, Novelli et al. 2020). In periods of great economic uncertainty, as the COVID-19 pandemic has already been proved to be (Baker et al. 2020), people tend to postpone childbearing (Kreyenfeld 2010, Kreyenfeld et al. 2012, Vignoli et al. 2020a), and long-lasting recessions negatively affect fertility 
intentions and behaviours, if they lead to an enduring or even permanent loss of income among young adults (Kearney and Levine 2020).

The expected and experienced worsening of economic conditions sum up with other indirect consequences of the COVID-19 pandemic, which might also negatively affect fertility intentions and behaviours such as the reduced availability of care services (both formal and informal) and the uncertainty about their future availability; the increased difficulties in accessing Assisted reproductive technology (ART) and reproductive health care (Beaujouan 2021, Lindberg 2020); an overall decline in the individual's subjective well-being (Zacher et al. 2020, Blasco-Belled et al. 2020), in the satisfaction with the work-family reconciliation (Mohring et al. 2020), and in the quality of the couple relationship (Panzeri et al. 2020, Luetke et al. 2020).

Following the call for ad hoc studies for understanding short-term demographic consequences of the COVID-19 pandemic (Beaujouan 2021), the aim of this paper is to examine the role of occupational status, experienced loss of income and expected worsening of income and occupational conditions due to the COVID-19 crisis on young Italians' fertility plans during the year 2020. Although some official statistics on births starts to be available at the aggregate level (see e.g., Blangiardo (2021) for Italy and Cohen (2021) and Sobotka et al. (2021) on other countries), our focus on fertility intentions allows assessing the role of the uncertainty about economic conditions created by the pandemic on the possible redefinition of individuals' fertility plans at the micro level. Macro-level fertility trends are informative on the overall possible short-term fertility effects of the pandemic, but they are limited in their ability to provide insights on the heterogeneities in these effects, which is crucial given that the pandemic's effects have been considerably unequal.

We use a unique longitudinal (repeated cross-sectional) dataset, collected at two different time points during the pandemic (March and October/November 2020) together with pre-COVID data (2016), to explore the changes in Italian young people's fertility intentions. More specifically, we consider fertility intentions under two alternative formulations: 1) the classical intention to conceive a child in the following 12 months, before and during the pandemic (i.e., in October 2016 and November 2020); 2) distinguishing between those who decided to confirm, postpone or abandon at least temporarily - the pre-pandemic fertility plans in March and October 2020, among those retrospectively reporting to have a plan in January 2020 for conceiving a child in the same year. The availability of the information on changes in fertility plans together with the standard fertility intentions question allowed us to draw a better understanding on how the pandemic has affected 
young Italians' fertility decisions. The information about the decision to postpone or abandon the pre-pandemic fertility plan, in fact, offers insights on possible mechanisms leading fertility postponement for which fertility behaviours would provide evidence only several years after the end of the pandemic. Because fertility intentions are strong predictors of fertility behaviours (Rindfuss et al. 1988, Schoen et al. 1999, Billari et al. 2009, Régnier-Loilier and Vignoli 2011), especially among younger individuals (Brzozowska and Beaujouan, 2020), focusing on changes in fertility intentions as short term effects of the pandemic also allows getting timely insights for policy makers to promptly act to reduce potential inequalities in the ability to realize the prepandemic fertility plans.

Italy was the first Western country hit by the pandemic, with one of the highest relative number of cases and deaths due to the COVID-19 till now (Natale et al. 2021). Additionally, compared to other Western European countries, in Italy the economic and social consequences of the 2008 Great Recession have been stronger and more long-lasting, mainly hitting the young population. In fact, in 2019 Italy showed one of the highest rates of youth unemployment $(22.4 \%$ among young people aged $15-29$ vs $11.4 \%$ in the EU27 $7^{4}$ ) and the highest proportion of NEET - i.e., young people neither in employment nor in education - in Europe (23.8\% among young people aged $15-34$ vs $14.0 \%$ in the EU $27^{5}$ ). Additionally, before the pandemic, Italy had the lowest fertility rate in the EU area (in 2019 was 1.27 in Italy vs 1.53 in the EU27 (provisional data; ${ }^{6}$ ). This means that the concerns about the demographic future of one of most rapidly ageing European country (the 2019 old-age dependency ratio - i.e., the number of persons aged 65+ per 100 persons aged 15-64 - was 35.8 in Italy vs 31.4 in the EU27 ${ }^{7}$ ) were already an issue before the COVID-19 pandemic (Caltabiano and Rosina 2018). The experienced and the expected economic shocks derived by the COVID-19 related economic crisis may accelerate the Italian demographic recession because the negative consequences of the COVID-19 pandemic add to an already unfavourable context for fertility.

\section{Economic recession and fertility behaviours and intentions}

The relationship between the economic cycle and fertility has long being studied. At least in highincome countries, fertility tends to reduce during recessions and to increase during or following periods of economic growth (e.g., Adsera and Menendez 2011, Comolli and Bernardi 2015, Cherlin

\footnotetext{
4 https://appsso.eurostat.ec.europa.eu/nui/show.do?dataset=yth_empl_100\&lang=en

5 https://appsso.eurostat.ec.europa.eu/nui/show.do?dataset=edat_lfse_20\&lang=en

$6 \mathrm{http}$ //appsso.eurostat.ec.europa.eu/nui/show.do?dataset=tps00199\&lang=en

$7 \mathrm{https} / /$ ec.europa.eu/eurostat/databrowser/view/tps00198/default/table?lang=en
} 
et al. 2013, Sobotka et al. 2011). The loss of job and income induce people to delay or withdraw their family plans: leaving parental home, buying or renting a house, getting married or having children (Kohler et al. 2002). In fact, all these plans imply substantial financial efforts. Children in particular come at a cost - of money, time and energy - which implies parents' long-term investments. For this reason, job and income stability is a precondition to make fertility plans (Kreyenfeld et al. 2012, Mills \& Blossfeld 2013, Vignoli et al. 2019).

Among high income countries, the procyclical relationship between economic conditions and fertility has been observed especially in the short term. Recessions usually negatively affect the period total fertility rate (Kiser and Whelpton 1953), but they tended to have marginal effects on the completed fertility of generations that experienced the crisis during their reproductive years (Sobotka et al. 2011, Lesthaeghe 2010, Matysiak et al. 2021, Cherlin et al. 2013).

Considering specifically recessions experienced in the last 50 years, they happened in a period of strong decline of fertility rates in Western countries, which has been mainly interpreted under the Second Demographic Transition framework, and in which the effect attributed to the economic turndowns per se was marginal (Kreyenfeld et al. 2012, Morgan et al. 2011, Sobotka et al. 2011). As for the 2008 Great Recession (Cherlin et al. 2013, Caltabiano et al. 2017), it has been shown that childbearing has been more frequently postponed in those contexts where the crisis hit the most especially among childless young individuals (Goldstein et al. 2013, Schneider 2015, Matysiak et al. 2021). Therefore, a short-term perspective on the consequence of a recession on fertility should focus on intentions instead of behaviours, to better understand whether a short-term reduction in fertility is driven by a postponement or a possible withdrawal from the original plans. However, few studies have specifically focussed on the relationship between recessions and fertility intentions. Most of them focused on the effect of the Great Recession (Testa and Basten 2014, Palumbo and Sironi 2016, Novelli et al. 2020, Fiori et al. 2018), finding that perceived and experienced job and income worsening due to the crisis is negatively influences fertility intentions.

\section{The impact of economic uncertainty on fertility intentions and behaviours}

In periods of economic recessions, economic uncertainty is amplified with detrimental consequences on fertility (see Vignoli and Comolli 2021). An enormous increase in economic uncertainty during the COVID-19 pandemic, has already been widely documented (Baker et al 2020, van der Wielen and Barrios 2020, Lambert et al. 2020; Magnusson et al. 2020; Reichelt et al. 2020). Economic uncertainty refers to "the individual risk factor, related to phases in the life course 
that are characterized by unemployment, part-time work, working on a term-limited contract, or difficulties entering the labour market in the first place" (Kreyenfeld et al. 2012, p. 838). Economic uncertainty has been traditionally defined and measured through labour market indicators such as being unemployed or being employed with a temporary contract (Kreyenfeld 2010; Kreyenfeld et al. 2012, Vignoli et al. 2012, Mills and Blossfeld 2013, Kreyenfeld 2016, Busetta et al. 2019, Vignoli et al. 2020a). Usually, casual, project-based, and seasonal works imply a low labour market integration and a wage penalty if compared with those employed with temporary or permanent contracts (Schmitt 2021). Moreover, the former jobs tend to bend more physically and mentally tiring, with non-standard working hours, which makes work-family balance particularly difficult (Benavides et al. 2000, Kalleberg 2009, Pirani 2017).

In most of the studies on the topic, evidence supports the existence of a negative effect of having a more precarious job on fertility (e.g., Dupray and Pailhé 2018, Lundstrom and Andersson 2012, Baizan 2005, Blossfeld et al. 2006, Pailhé and Solaz 2012) and fertility intentions (Pailhè 2009, Palumbo and Sironi 2016, Modena and Sabatini 2012). However, having an unstable job is not always linked to a higher vulnerability to recession periods: some temporary contracts are very well-paid, and this might be seen as an opportunity, which does not have negative returns in terms of fertility (Alderotti et al. 2019). This strictly depends on contextual characteristics such as the structure of the labour market and the welfare system, which can act as institutional filters (Mills and Blossfeld 2005). In a context of institutional and welfare state weakness, a condition of economic uncertainty is much likely to negatively impact on fertility decisions, as found by Novelli and colleagues (2020) in Italy where during the Great Recession, precarious work conditions negatively affected fertility intentions.

Together with objective indicators related to labour market and economic conditions, an increasing number of studies on fertility intentions and behaviours also considers the role of subjective indicators of economic uncertainty (Bhaumik and Nugent 2011, Fahlén and Oláh 2018, Hofmann and Hohmeyer 2013, Kreyenfeld 2010, Kreyenfeld et al. 2012, Witte and Wagner 1995, Novelli et al. 2020, Vignoli et al. 2020a, 2020b). Economic and labour market deterioration is associated with an increase in perceived economic insecurity and occupational instability, and the individuals' perception and expectation may be of particularly relevance for fertility intentions on top of objective economic conditions (Busetta et al. 2019, Modena et al. 2013). As highlighted in the literature (e.g., Testa and Basten 2014), in fact, perceptions and expectations even more than the actual impact of the recession on individuals' current occupational and income conditions can shape 
fertility plans. Thus, our study focuses on the subjective dimensions of economic uncertainty, intended as individuals' expectations about their future income and occupational insecurity.

The multiplying effect of recessions on uncertainty has been particularly intense for the crises of the last 50 years (Testa and Basten 2014), because the uncertainty due to the recessions summed up with a widespread general feeling of vulnerability brought by the globalization process (Mills and Blossfeld 2005). Thus, economic uncertainty has become an important factor for explaining fertility postponement and decline since the 1980s (Sobotka 2003, Kreyenfeld et al. 2012, Comolli 2017, Comolli et al. 2020, Vignoli et al. 2020b, Comolli and Vignoli 2021, Matysiak et al. 2021, Hofmann et al. 2017). In Western societies in general, but especially in Southern European countries, markets deregulation and the delocalization of economic activities (Hofmeister et al. 2006, Blossfeld et al. 2006) has increased economic and occupational uncertainty, which has been found to be related with the postponement of the transition to parenthood and the reduction of fertility (Kreyenfeld et al. 2012, Mills and Blossfeld 2013). Furthermore, the relationship between economic uncertainty and fertility has become stronger over time and it has been especially powered by the 2008 Great Recession. This happened in particular in countries, such as Italy, where the institutions were unable to buffer the negative effects of the changes in the labour market due to globalization (de-regulation, delocalization etc.) on the individuals' perceptions of uncertainty (Alderotti et al. 2019).

\section{The Italian case}

During the 1980s, the Italian labour market has witnessed a strong deregulation, characterized by increasing forms of flexible and unstable employment usually consisting in jobs with limited duration and low income (Emmenegger et al. 2012). These kinds of jobs are usually associated with lower occupational prospects and careers (Barbieri \& Scherer, 2009), higher risk of entering poverty (Barbieri and Bozzon, 2016) and of turning into unemployment during recession periods (Liotti 2020). Women and young individuals have been the groups of workers mostly affected by these changes in the Italian labour market (Brandolini et al. 2007, Barbieri and Scherer 2005). Moreover, as a long-lasting consequence of the 2008 financial crisis, the proportion of NEET (young people Neither in Employment nor in Education or Training) has increased in Italy (Amendola 2021). The vulnerability associated with the NEET condition is especially high in this context, because the proportion of individuals in long-term unemployment or discouraged in the job search (i.e., no longer actively looking for a job, but still available to work) is much higher in Italy 
than in other European countries (Mascherini and Ledermaier 2016), where the NEET condition is more often a temporary status.

Another factor that contributes creating an unfavourable context for fertility in Italy is related to traditional gender roles (Arpino et al. 2015). Previous studies have widely documented the positive relationship between female participation to the labour force and fertility behaviours and intentions (e.g., Ahn and Mira 2002, Rindfuss et al. 2003, Engelhardt et al. 2004). However, in Italy female labour force participation remains low (European Commission, 2019), also because of a lack of accessible and affordable childcare services (Del Boca and Vuri 2007, Brilli 2017), which makes it difficult to reconciliate work and family obligations (Barbieri et al. 2015).

In this context, where occupational vulnerability is a widespread condition among young people, gender norms are not egalitarian and the welfare state is not supportive of families, fertility plans of individuals with poor economic prospects are particularly at risk. In fact, Italian studies have found that precarious job conditions are strongly related to fertility postponement (Vignoli et al. 2012, 2020a) and to reduced fertility intentions (Busetta et al. 2019, Modena and Sabatini 2012, Modena et al. 2013).

The above described unfavourable pre-COVID context for fertility has been further worsened by the pandemic. Italy has been the first country outside Asia to be severely hit by the pandemic and it was also the first country to implement a nationwide lockdown in March 2020, which has been one of the strictest and longest worldwide (Hale et al. 2020; Plümper and Neumayer 2020). Schools and non-essential workplaces were closed, events and public gatherings were prohibited, as well as nonessential movements (Plümper and Neumayer 2020). Following lockdowns have been limited to specific areas (communes or provinces), but restrictive measures have been adopted in in the whole country in October 2020 to fight the second wave of the pandemic. These restrictive measures had strong negative impacts on individuals' psychological wellbeing (Arpino et al 2020; Orgilés et al. 2020), as well as on employment and income conditions and future prospects. While a global economic contraction in the GDP for the year 2020 is estimated at 3.5\%, this is expected to be even stronger for the Euro area (7.2\%) and for Italy in particular (9.2\%; IMF 2021). In Italy the cushion provided by the suspension of the layoffs have limited the short-term effects of COVID-19 on the labor market (Colussi 2020). Therefore, there has not been an increase in the unemployment rate, but national statistics (ISTAT 2021) report a drop in the percentage of employed individuals (-1.9 percentage points (pp) during the year 2020), largely due to fixed term contracts not being renewed. 
Also, the percentage of economically inactive people has increased, especially among women $(+2$ $\mathrm{pp}$, versus $+1 \mathrm{pp}$ for men) and individuals aged 25-34 (+8.3 pp, against an average of $3.8 \mathrm{pp}$ for the whole population). Some studies show that during the pandemic, Italians (Eurofound 2020), and especially young Italians (Luppi and Rosina 2020), expected a negative impact of the COVID crisis on their income, work and career. According to Luppi and Rosina (2020), in October 2020, almost $45 \%$ of women and $35 \%$ of men expected a drop in family income and work career because of the recession.

\section{The impact of the COVID-19 pandemic on births and fertility intentions}

Against the previous discussion on the role of economic uncertainty during recessions and on the Italian context, a reduction in fertility can be expected. Studies on Italy and on other developed countries have already shown some evidence of that (Cohen 2021, Li et al. 2021, Sobotka et al. 2021; Lindeberg et al. 2020, Luppi et al. 2020, Luppi and Rosina 2020, Guetto et al. 2020, Micelli et al. 2020, Blangiardo 2021), while studies on low and medium-income countries (Emery and Koops 2021, Zhu et al. 2020) found mixed effects of the pandemic on fertility intentions. In Italy, first data released by ISTAT $^{8}$ shows that, compared to the same months of the previous year, in December 2020 the number of births declined by $10.3 \%$; this is the first month in which the effects of the first epidemic wave are observable. This trend has been anticipated by studies on fertility intentions conducted soon after the beginning of the health emergency in March 2020. In particular, Luppi and colleagues (2020) show that at the beginning of the health emergency in March 2020, across European countries, a high proportion of young individuals of prime reproductive age (18-34 years old; Brzozowska and Beaujouan, 2020) were postponing or indefinitely suspending the original intention of having a child during the 2020. In particular, in Italy the percentage of those who (at least) temporarily abandoned the fertility plan for the year 2020 was much higher than in France and Germany, and in general it was the highest in the group of countries included in the study. Another study conducted in the same period (Micelli et al. 2020) on an Italian sample of women and men (18-46 years old) found that $37 \%$ of the interviewed individuals who were planning to have a child before the pandemic abandoned their plan, most of them because of worries about future financial difficulties brought by the recession. On the same line, Guetto and colleagues (2020), by conducting a survey on Italian individuals of reproductive ages and using online experiments on shared narratives of the future, found that pre-pandemic fertility intentions decrease with the increase of the expected length of the health emergency. The authors also argue that a long-lasting economic recession may determine a possible drop in fertility, but that this effect

8 Available at: $\underline{\text { https://www.istat.it/it/files//2021/03/REPORT-IMPATTO-COVIDDEMOGRAFIA_2020.pdf }}$ 
might became more visible after the second pandemic wave. All these studies, in fact, have been conducted during the nationwide lockdown of March 2020.

Our study offers a twofold contribution to this preliminary evidence on the consequences of the pandemic on fertility. First, we examine the heterogeneity in the consequences of the economic uncertainty created by the pandemic on changes in fertility plans by studying the role of experienced and expected income and occupational vulnerabilities due to the COVID-19 crisis in Italy. Second, our analyses are not limited to the very first period of the pandemic as most previous contributions, but we also exploit data collected in October and November 2020. Also, we exploit pre-COVID data (2016) for the sake of comparing the pandemic context with a pre-pandemic period.

\section{Data and method}

Data

Data used for the analyses come from the Rapporto Giovani survey, carried out by the Osservatorio Giovani of Istituto Toniolo, in collaboration with IPSOS. The survey started in 2011 and uses CAWI (Computer Assisted Web Interviewing) administered questionnaires. The survey includes both regular and special cross-sectional waves: the regular module (the core of the study) is repeated every year; the special modules are carried out as independent surveys on ad hoc topics. In this paper, we exploit the COVID waves and a pre-COVID regular wave from the 2016 that is the most recent pre-pandemic wave including a fertility intention question that is comparable to the question included in the regular 2020 wave. In this way we exploit two different approaches to assess changes in fertility plans during the COVID-19 pandemic based on: 1) retrospective questions in the COVID waves; 2) repeated questions in October 2016 and November 2020 regular modules.

The two special cross-sectional COVID waves have been administered on independent samples of individuals between March 27-31and again in October 5-14 2020. In all surveys, individuals are chosen with a quota sampling technique targeting the young population (18-34 years old individuals) ensuring the representativeness with respect to a significant set of key variables (gender, age, geographical origin, education, marital status, etc.) on which the quotas are defined ${ }^{9}$. We select our working samples by excluding full-time students because they represent a nonhomogeneous category of individuals, including both those who just started their academic studies and those who are about to exist the educational system. Additionally, we do not have information 9 More information is available at: https://www.rapportogiovani.it/osservatorio/ 
on whether they are actively looking for a job. This information would be relevant because students might give a very different meaning to the expectation about the impact of the current crisis on their future occupation and financial situation, depending on how close they plan to enter the labour market. By excluding students, the sample sizes were 4573 (wave 2016), 4580 (wave 2020), 1491 (COVID-wave March 2020), and 1492 (COVID-wave October 2020). Then, the regular waves (2016 and 2020) have been pooled and only individuals with intentions to conceive within 3 or 2 years have been considered for the multivariate analyses $(\mathrm{N}=3286)$. The COVID waves have also been pooled and only individuals who declared to have a plan to conceive a child in January 2020 have been selected $(\mathrm{N}=758)$. More details on the samples' composition are available in the Results section.

\section{Dependent variable based on the 2016 and 2020 regular waves}

To compare the 2016 and 2020 fertility intentions we consider the short-term intentions collected through the question "Do you expect to conceive a child within the next 12 months?" with four possible answers: "Surely not", "Maybe not", "Maybe yes" and "Surely yes". The question has been asked only to individuals who answered that they intend to conceive a child in the following 3 years (in the 2016 survey) or 2 years (in the 2020 survey). This different time frame might imply a possible overestimation of fertility intentions in 2016 . However, these data provide a good measure on the short-term intention of conceiving a child. Although these questions are not strictly comparable because of the different time horizon, the sub-questions using a 1-year time frame are comparable and we focus on them.

\section{Dependent variable based on the COVID waves}

In order to get information on respondents' fertility plans before the COVID-19 emergency, the following question has been asked:

a. "At the beginning of the year [2020], i.e., shortly before the coronavirus emergency broke out, were you planning to conceive/have a baby before the end of 2020?", using the possible alternatives [1a] "No", [2a] "I was considering it but without having planned it", [3a] "Yes, I had planned it". Only for the October wave a further possible answer has been added [4a] "Yes, I've both planned and realized it", for those who were able to conceive a child during 2020. 
Respondents who declared to be planning to have a child during the 2020 (i.e., answers [2a] or [3a] in the March wave; answer [3a] in the October survey), have also been asked the following question:

b. "Did the coronavirus emergency interfere in any way with this program?" with three possible answers: [1b] "No, the program remains confirmed for 2020"; [2b] "The program remains confirmed but I had to postpone it"; [3b] "For now I have quit the program".

Therefore, our second dependent variable is a three-level categorical variable corresponding to the following groups of individuals:

I. those who realized their plan [4a], those who were planning or were considering the idea to conceive/having a child during the 2020 and that confirmed their plan [1b] (i.e., stillplanners);

II. those who were planning or were considering the idea to conceive/having a child during the 2020 and that postponed the plan [2b] (i.e., postponers);

III. those who were planning or were considering the idea to conceive/having a child during the 2020 and that have quitted the plan [3b] (i.e., abandoners).

Notice that, obviously, in the October wave, those who reported to have already realized the original plan have no counterpart in the March wave and have been considered together with those who confirmed the original fertility plan. Also, the filter to the question on the confirmed and revised fertility plans changed between the two survey waves. In March, this question has been asked to both those who - in January 2020 - declared strong [3a] and weaker intentions [2a] to conceive a child during the next 12 months; in October, the question has been asked only to those with strong intentions [3a]. In the following, we will focus on the "enlarged" sample that includes those with weaker intention in March 2020. However, we have considered a robustness check on the "restricted" sample that only includes those with stronger intentions both in March and October 2020. Additionally, because there might be a selection among those who retrospectively declared to have fertility plans in January 2020, further robustness checks have been implemented by modelling the probability of being among those with no fertility plans in January 2020 (all results from robustness checks are in the Supplementary Materials).

\section{Explanatory variables}

The three main independent variables are represented by: 1) occupational status; 2) the self-reported actual effect of the COVID-19 emergency on the respondent's financial situation; 3) the perceived 
expected effect on future personal income and occupation. While all the explanatory variables are available in the COVID waves, in the regular 2016 and 2020 survey only occupational status is available.

The occupational condition of the respondents, considering both the fact that they are working or not and the level of protection of their occupation, is operationalized by classifying individuals in three groups:

I. those who are not working and not studying (NEET): they represent the most vulnerable group in terms of personal income protection because they are out of the labour market. This category includes both individuals actively looking for a job, those who are available to work but they are not searching for a job (e.g., discouraged unemployed persons), and those who are not available to work at the moment of the interview (e.g., because of care responsibilities);

II. those who are working as self-employed (excluding professionals), with a project-based contract, causal workers and low-skilled autonomous workers: they are vulnerable both in terms of income and occupation protection. Compared to employees with non-permanent contracts, they tend to have lower wages and consequently lower social security contributions. Also, they do not benefit from employment protection legislation (Brandolini et al 2007);

III. those who are working as employees (with either permanent or non-permanent contracts), professionals and managers: they are those with the highest level of protection of both their income and occupation. Clustering together employees with permanent and non-permanent contracts is consistent with the evidence that the proportion of those still-planning, postponing or abandoning the fertility plan for the 2020 is similar between the two groups ${ }^{10}$.

Regarding the self-reported effect on the financial situation, the question has been posed as follows: "Compared to before the coronavirus emergency, your financial situation today: [1] has worsened a lot; [2] has slightly worsened; [3] nothing has changed; [4] has slightly improved; [5] has improved a lot". The variable has been dichotomized taking value 1 in the case the respondents report their financial situation as worsened and 0 otherwise.

10 Tests of differences between proportions did not reject the null hypothesis of equality between the proportions of still-planning/postponing/abandoning individuals between the two groups of employees with and without a permanent contract. 
As for the expected future effects, respondents answered to the question "Thinking about your future, do you think the current coronavirus emergency will have a positive or negative impact on: your (personal) income / your occupation?" on a scale scoring from 1 (much negative) to 5 (much positive). The variable has been dichotomized, taking value 0 if the respondents expect a positive effect or null effect (values 3, 4 and 5), and value 1 in case the respondents expect negative returns in terms of income /occupation (values 1 and 2).

\section{Control variables}

We control for the age of the respondent dividing the age range into 3 intervals (i.e., 18-24; 25-29; 30-34) to better catch possible life-cycle effects. Additionally, we also control for the marital status (married and cohabiting individuals vs other conditions), the presence of children in the household, and education (having or not a tertiary level degree). Unfortunately, there is no information on age and number of children. We also control for living in a geographical area characterized by high level of diffusion of the COVID-19. Data on the diffusion of the COVID-19 have been collected at the regional level (NUTS2). In particular, our indicator is the cumulated number of confirmed cases of COVID- $19^{11}$ on the total amount of the population in the region (per 1000 inhabitants). By calculating the tertiles of the distribution, separately for the two survey waves, a control dummy variable for living in a region with high number of cumulated cases of COVID-19 has been added (regions above the second tertile). Both in March and in October, these regions were: Valle d'Aosta, Emilia-Romagna, Liguria, Lombardia, Piemonte, Trentino Alto-Adige and Veneto.

\section{Method}

We implement two distinct modelling strategies to contrast fertility intentions before and after the pandemic by exploiting data in the regular waves (2016-2020) and in the COVID waves (March and October 2020). Given the ordered nature of the dependent variable measuring fertility intentions available in the regular waves, we use generalized ordered logit models by polling the two samples and including the occupational status - interacted with the survey year - as the main explanatory variable and the socio-demographic controls previously mentioned.

11 Source: https://github.com/open-covid-19/data\#metadata, https://www.data.gouv.fr/fr/reuses/carte-de-levolution-ducovid-en-france/, https://coronavirus.data.gov.uk/\#regions, http://www.salute.gov.it/portale/nuovocoronavirus/dettaglioContenutiNuovoCoronavirus.jsp? $\underline{\text { area }=\text { nuovoCoronavirus } \& i d=5351 \& \text { lingua }=\text { italiano\&menu }=\text { vuoto }}$ 
Instead, the categories of the second dependent variable on whether pre-pandemic fertility plans have been confirmed, postponed or abandoned do not follow a natural order. Therefore, data from the COVID waves, have been analysed using multinomial models. In this way, it is also possible to assess the separate effects of explanatory variables on each category of the dependent variable. In order to use a larger sample size, the analyses are conducted by pooling the March and October waves and controlling for the timing of the survey (reference: March 2020). We first run a model that includes all control variables and the occupational status. Then, additional models add in turn one of the subjective indicators of economic uncertainty. To test possible differences in the relationship between our main independent variables and the categories of the dependent variable, we add interactions between the main covariates and the wave indicator. We do not find statistically significant results except for the occupational status. Therefore, while for the subjective indicators of economic uncertainty results are presented without including the interaction with the wave, for the occupational status the results for the interaction terms are shown.

To ease interpretation of findings, all results are presented graphically by showing predicted probabilities. Full tables of estimated coefficients are available in the Supplementary Materials (Tables from 3A to 7A).

\section{Results}

\section{Descriptive statistics}

In Table 1 and Table 2 we report the samples sizes and the distribution of the dependent variables in the regular waves (2016 and 2020) and in the COVID waves (March and October 2020), respectively. The distribution of the main covariates and the control variables are in the Supplementary Materials (Tables 1A and 2A).

About the samples of the 2016 and 2020 regular waves, Table 1 shows that in 2016 , almost $40 \%$ of the respondents do intend to have a child in the following 3 years; in 2020 the percentage of individuals who intend to have a child in the short-term ( 2 years) is about 32\%. Among those with a positive short-term ( 3 or 2 years) fertility intention, in 2016, about $36 \%$ intend to have a child within 12 months (those answering probably or surely yes), while in 2020 this percentage is about $43 \%$. If we calculate these percentages on the total samples (excluding students) we get very similar values: $14.5 \%$ and $13.8 \%$, respectively. Thus, the positive fertility intentions within 1-year are very similar in 2016 and 2020. 
Data from the pooled samples in the COVID waves (Table 2) show that almost $68 \%$ of the respondents declare that they did not intention to conceive a child in the next 12 months in January 2020. Among the remaining 32\%, the percentage of those confirming, postponing or abandoning the fertility plans as a consequence of the pandemic occurrence has been calculated both in the restricted and the enlarged samples. By comparing the restricted samples of March and October, we contrast groups of respondents selected with the same criteria (i.e., including only those with a precise fertility plan in January 2020), which checking the comparability of the two samples. In the restricted sample we find that the distribution of changes in fertility plans is similar in the two periods: in October, about $45.7 \%$ of the respondents (48.5\% in March) confirms the original plan of conceiving a child during the 2020, the rest of respondents intends to postpone or to indefinitely abandon the original plan. The proportions of postponers and abandoners slightly vary between the two surveys, with a little increase in the percentage of postponers (from about $27.3 \%$ to $37.4 \%$ ) and a correspondent decline for the abandoners (from about $24.2 \%$ to $16.9 \%$ ).

Table 1. Samples' size and distribution of the dependent variables, main covariates and control variables for the regular waves (2016 and 2020); separated and pooled samples.

\begin{tabular}{|c|c|c|c|}
\hline & \multicolumn{3}{|c|}{ Regular waves } \\
\hline & 2016 & 2020 & Pooled \\
\hline Original sample size & 6172 & 7012 & 13184 \\
\hline Sample size without students & 4573 & 4580 & 9153 \\
\hline \multicolumn{4}{|c|}{ Intention to conceive a child within $2 / 3$ years } \\
\hline \multirow[t]{2}{*}{ Yes } & $39.78 \%$ & $32.03 \%$ & $35.90 \%$ \\
\hline & 1819 & 1467 & 3286 \\
\hline \multicolumn{4}{|c|}{ Intention to conceive a child within 12 months ${ }^{a}$} \\
\hline Surely not & $21.94 \%$ & $17.66 \%$ & $20.02 \%$ \\
\hline Probably not & $41.62 \%$ & $39.20 \%$ & $40.54 \%$ \\
\hline Probably yes & $26.61 \%$ & $33.61 \%$ & $29.73 \%$ \\
\hline Surely yes & $9.84 \%$ & $9.54 \%$ & $9.71 \%$ \\
\hline
\end{tabular}

Notes:

${ }^{a}$ only for those with $2 / 3$ years fertility intentions 
Table 2. Samples' size and distribution of the dependent variables, main covariates and control variables for the COVID waves (March and October 2020); separated and pooled samples.

\begin{tabular}{|c|c|c|c|}
\hline & \multicolumn{3}{|c|}{ COVID waves } \\
\hline & March & October & Pooled \\
\hline Original sample size & 2000 & 2000 & 4000 \\
\hline Sample size without students & 1491 & 1492 & 2983 \\
\hline \multicolumn{4}{|l|}{ Retrospective fertility plans in January 2020} \\
\hline With no fertility plans (no-plans) & $70.10 \%$ & $65.20 \%$ & $67.68 \%$ \\
\hline With some possible plans & $18.90 \%$ & $11.20 \%$ & $12.54 \%$ \\
\hline With a precise plan & $11.00 \%$ & $16.70 \%$ & $13.91 \%$ \\
\hline With a plan that has been realized & - & $6.90 \%$ & $3.45 \%$ \\
\hline \multicolumn{4}{|l|}{ Sample size without no-plans ${ }^{\mathrm{a}}$} \\
\hline enlarged sample ${ }^{b}$ & 445 & 313 & 758 \\
\hline restricted sample ${ }^{\mathrm{c}}$ & 165 & 313 & 478 \\
\hline \multicolumn{4}{|l|}{ Revised/confirmed fertility plans in the enlarged sample } \\
\hline Still-planners (considering also the realized plans in October) & $28.54 \%$ & $45.69 \%$ & $35.62 \%$ \\
\hline Postponers & $38.00 \%$ & $37.38 \%$ & $37.99 \%$ \\
\hline Abandoners & $33.03 \%$ & $16.93 \%$ & $26.39 \%$ \\
\hline \multicolumn{4}{|l|}{ Revised/confirmed fertility plans in the restricted sample } \\
\hline Still-planners (considering also the realized plans in October) & $48.49 \%$ & $45.69 \%$ & $47.13 \%$ \\
\hline Postponers & $27.27 \%$ & $37.38 \%$ & $32.83 \%$ \\
\hline Abandoners & $24.24 \%$ & $16.93 \%$ & $20.04 \%$ \\
\hline
\end{tabular}

\section{Notes:}

${ }^{a}$ considering only those answering the question regarding the revised/confirmed fertility plans

${ }^{\mathrm{b}}$ considering also those "with some possible plans" in March 2020

${ }^{c}$ excluding those "with some possible plans" in March 2020

Comparing the 2016 and 2020 fertility intentions in the regular waves

Although we do not observe substantial differences in fertility intentions between the 2016 and 2020 samples as it might be expected because of the 2020 COVID-19 emergency, a variation can be found when looking at the occupational condition of the respondents. In particular, by running a generalized ordered logit model for the intention to conceive a child in the following 12 months by gender, we contrast the predicted probabilities of fertility intentions by occupation in 2016 and 2020 (complete models are in Supplementary Materials, Table 3A). Because we do not find significant variations for the other categories of the outcome variable, Figure 1 shows the predicted probabilities corresponding to the extreme category "surely yes". The figure shows that the generally most vulnerable workers (i.e., self-employed and temporary) in 2020 report a lower 
probability of definitively intending to have a child in the short-term as compared to their counterparts in the 2016. This pattern is evident for both genders, and it comes out as statistically significant (at the 5\% level) for women (with a predicted probability of $16 \%$ in 2016 vs $3 \%$ in 2020 ) and for men (at 10\% level, with a predicted probability of $17 \%$ in 2016 vs $5 \%$ in 2020). On the contrary, for those with a safer employment situation the probability of intending to have a child "for sure" within the 12 months has not substantively (nor statistically significantly) changed for men, and for women it is even slightly higher in 2020 than in 2016 (respectively 16\% vs 11\%, significant at the $5 \%$ level).

Figure 1. Predicted probabilities of intending to have a(nother) child "surely yes" in the next 12 months by occupational condition in 2016 and 2020 and by gender with confidence intervals for pair-wise comparisons at the $10 \%$ significance level

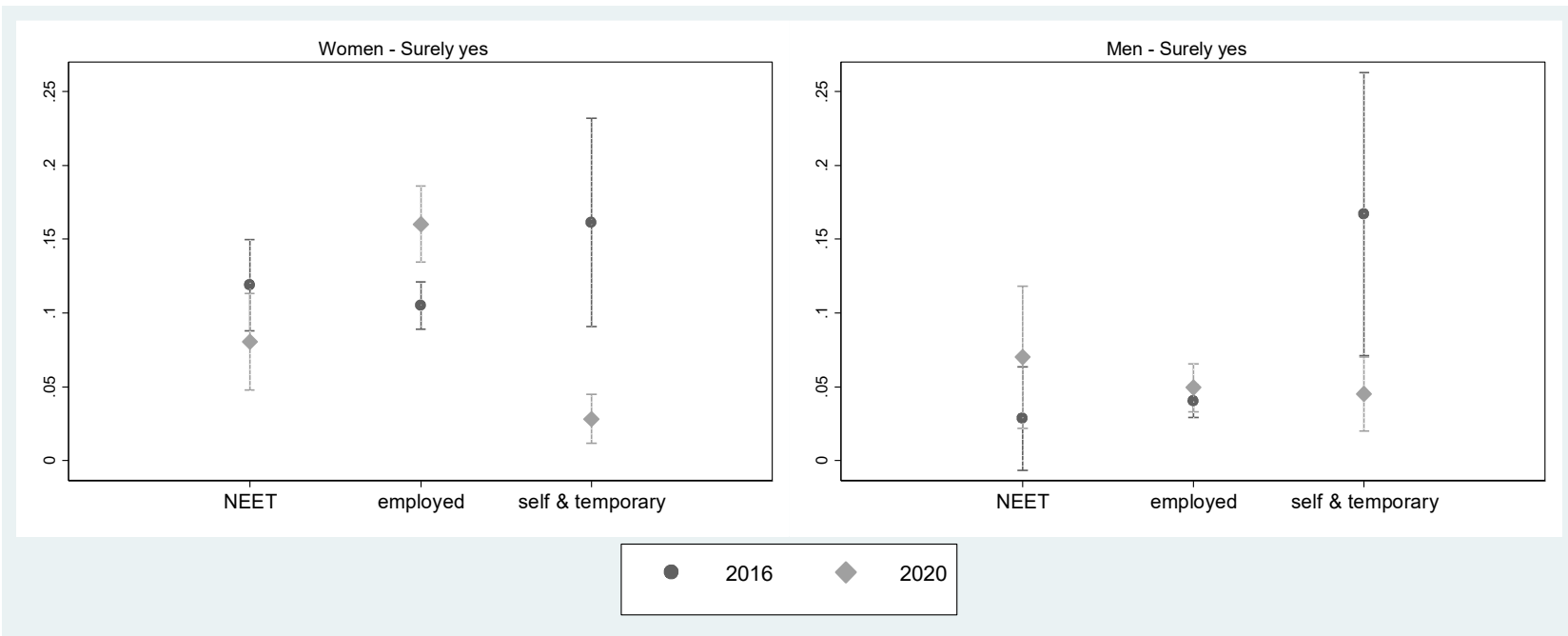

Note: Predicted probabilities bases on a generalized ordinal logit model, controlling for age class, education, marital status, presence of children, among those intending to have a child in the next 2 years (2020) or 3 years (2016). Full results are available in Table 3A in Supplementary Materials. Displayed confidence intervals allow having an average level of $10 \%$ for the Type I error probability in the pair-wise comparisons of predicted values. When differences of interest are significant at the $5 \%$ level, this is noticed in the text.

\section{Revised fertility plans in the COVID waves}

We now turn to the COVID waves that allow examining self-reported changes in pre-COVID fertility plans. We first examine whether the occupational status is associated with the probability to confirm, postpone or abandon the fertility plan respondents had in January 2020, by gender (Figure 3, Model 1 in Table 6A and 7A in the Supplementary Materials). Figure 2 shows that in March a more precarious occupational condition is associated (at the 5\% level) with a higher chance of abandoning the original plan compared to October. In particular, for women in March the probability of abandoning the fertility plans is about $46 \%$ for self-employed and temporary workers 
and $43 \%$ for NEET (vs $29 \%$ for employees). Correspondently, a lower probability to confirm the pre-COVID plans arises in March (19\% for self-employed and temporary workers, $26 \%$ for NEET vs $36 \%$ for employees). In October the probability for women to abandon the fertility plan is $16 \%$ for both the vulnerable occupation categories, and it is no longer significantly different from the same probability for the employees. For men, the chances of abandoning the plan for self-employed and temporary workers are significantly higher in March (54\%) than in October (16\%) and compared to the other two occupational categories in March (NEET 28\% and employees 23\%), while the difference is no longer significant in October. Finally, the probability to confirm the fertility plan is lower for self-employed and temporary workers in March (9\%) compared to October $(38 \%)$ and to NEET (26\%) and employees (33\%) in March.

Figure 2. Predicted probabilities of changes or confirmation of pre-COVID fertility plans in March and October 2020 and across occupational conditions, with confidence intervals for pair-wise comparisons at the $10 \%$ significance level
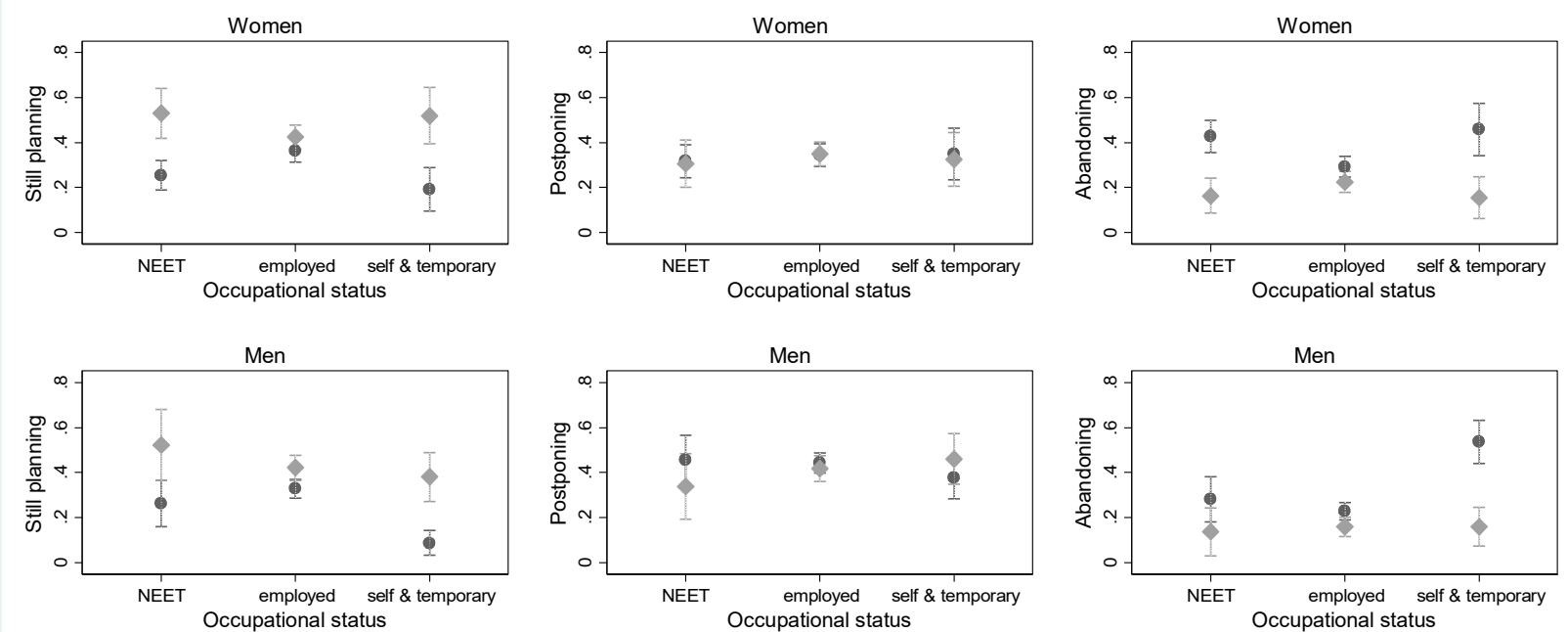

- March 2020

October 2020

Note: Predicted probabilities bases on a multinomial logit model, controlling for age class, education, marital status, presence of children. Full results are available in Tables 6A and 7A in Supplementary Materials. Displayed confidence intervals allow having an average level of 5\% for the Type I error probability in the pair-wise comparisons of predicted values. No differences in terms of significancy has been found with confidence intervals at $10 \%$.

Figures 3 to 5 show the results from models where the subjective indicators of economic uncertainty have been added one by one (complete estimates are reported in Tables 4A and 5A, Models from 2 to 4, of the Supplementary Materials). For both genders, but especially for women, Figure 3 shows an association between having experienced a drop in the income and the changes in fertility plans (confidence interval for pair-wise comparisons at 5\% level). In particular, individuals who report a worsened financial situation display a higher probability to abandon their fertility 
plans for the 2020 as compared to individuals who did not experience such an income shock (respectively $36 \%$ vs $21 \%$ among women and $30 \%$ vs $20 \%$ among men). Among women, a worsened financial situation is also negatively associated with the probability of confirming the fertility plan (32\% for those who did experience worsened financial situation vs $43 \%$ for those who did not).

Figure 3. Predicted probabilities changes or confirmation of pre-COVID for those who experienced and those who did not experience a worsening in their financial situation with confidence intervals for pair-wise comparisons at the $5 \%$ significance level
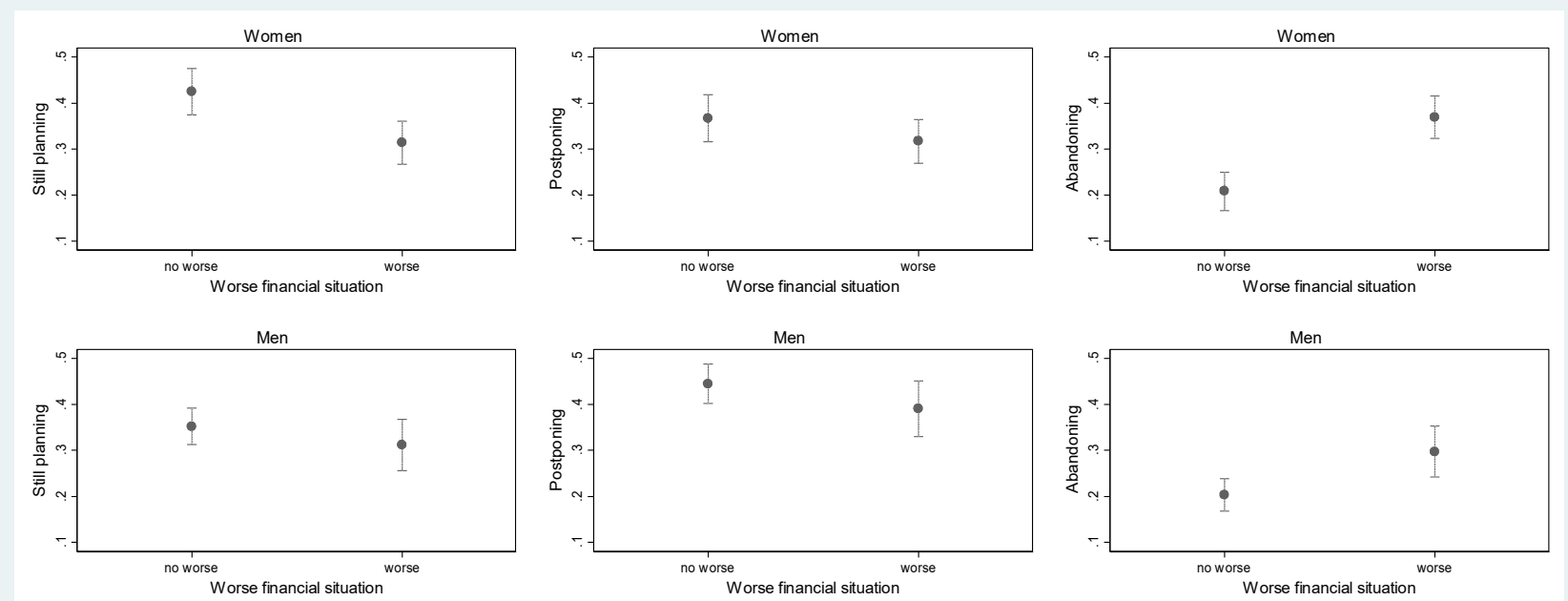

Note: Predicted probabilities bases on a multinomial logit model, controlling for age class, education, marital status, presence of children. Full results are available in Tables 4A and 5A in Supplementary Materials. Displayed confidence intervals allow having an average level of 5\% for the Type I error probability in the pair-wise comparisons of predicted values. No differences in terms of significancy has been found with confidence intervals at $10 \%$.

Finally, Figures 4 and 5 present results regarding the expectations about the future effect of the recession on the individual's occupation and income, respectively (confidence interval at 5\% level). Women who perceive their occupation as at risk because of the COVID-19 crisis are less likely to confirm their pre-crisis fertility plans as compared to their counterparts who do not hold such a negative expectation (respectively $34 \%$ vs $42 \%$, Figure 4). Correspondingly, women who expect their occupation to be at risk show a considerably higher probability of declaring to abandon their original fertility plans for the 2020 (respectively 32\% vs 24\%, Figure 4). Similarly, both women and men who perceive their future income to be at risk due to the COVID-19 crisis show a lower probability of confirming and a higher probability of abandoning the pre-pandemic fertility plan (Figure 5). More specifically, the probability of abandoning the pre-COVID fertility plan for women who expect the pandemic to produce a negative shock on their income in the future is $36 \%$ 
against $23 \%$ for those who do not hold such a negative expectation. For men, we observe a slightly lower but still sizeable gap (29\% vs $20 \%)$.

Figure 4. Predicted probabilities of changes or confirmation of pre-COVID fertility plans by expectations on whether future occupation is at risk with confidence intervals for pair-wise comparisons at the $5 \%$ significance level
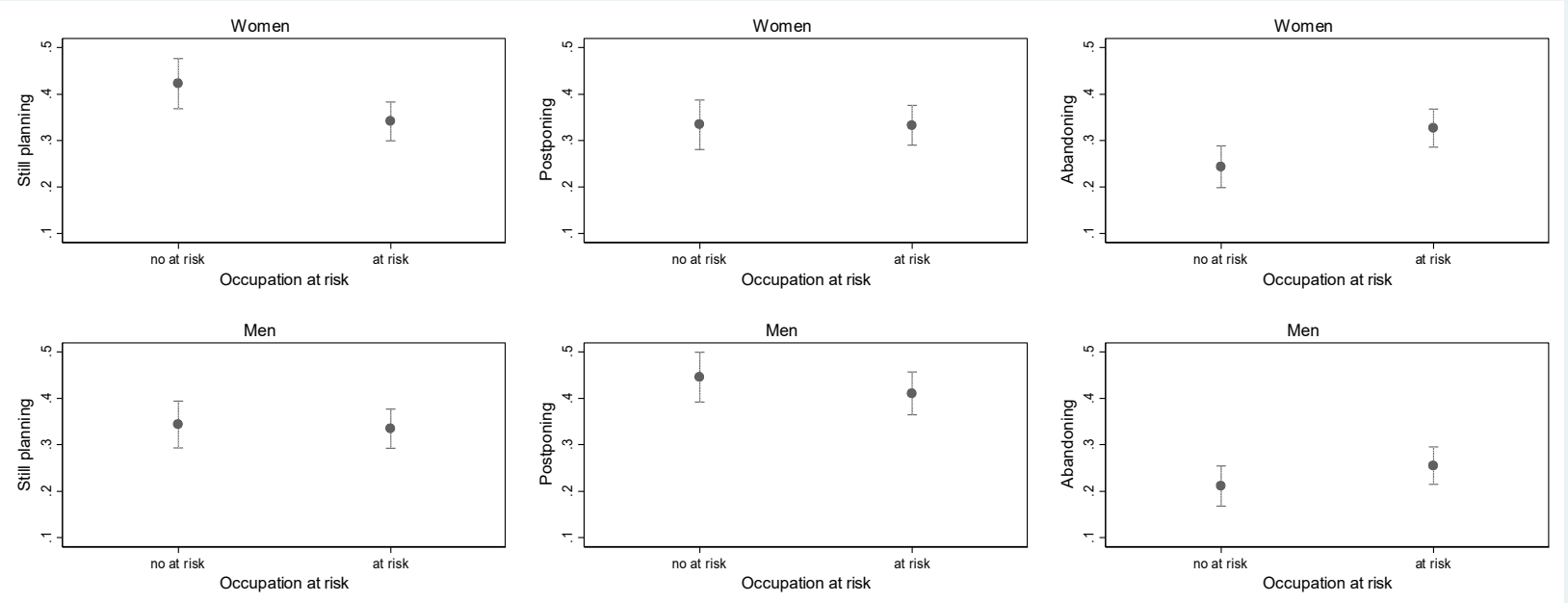

Note: Predicted probabilities bases on a multinomial logit model, controlling for age class, education, marital status, presence of children. Full results are available in Tables 4A and 5A in Supplementary Materials. Displayed confidence intervals allow having an average level of 5\% for the Type I error probability in the pair-wise comparisons of predicted values. No differences in terms of significancy has been found with confidence intervals at $10 \%$.

Figure 5. Predicted probabilities of changes or confirmation of pre-COVID fertility plans by expectations on whether future income is at risk with confidence intervals for pair-wise comparisons at the $5 \%$ significance level
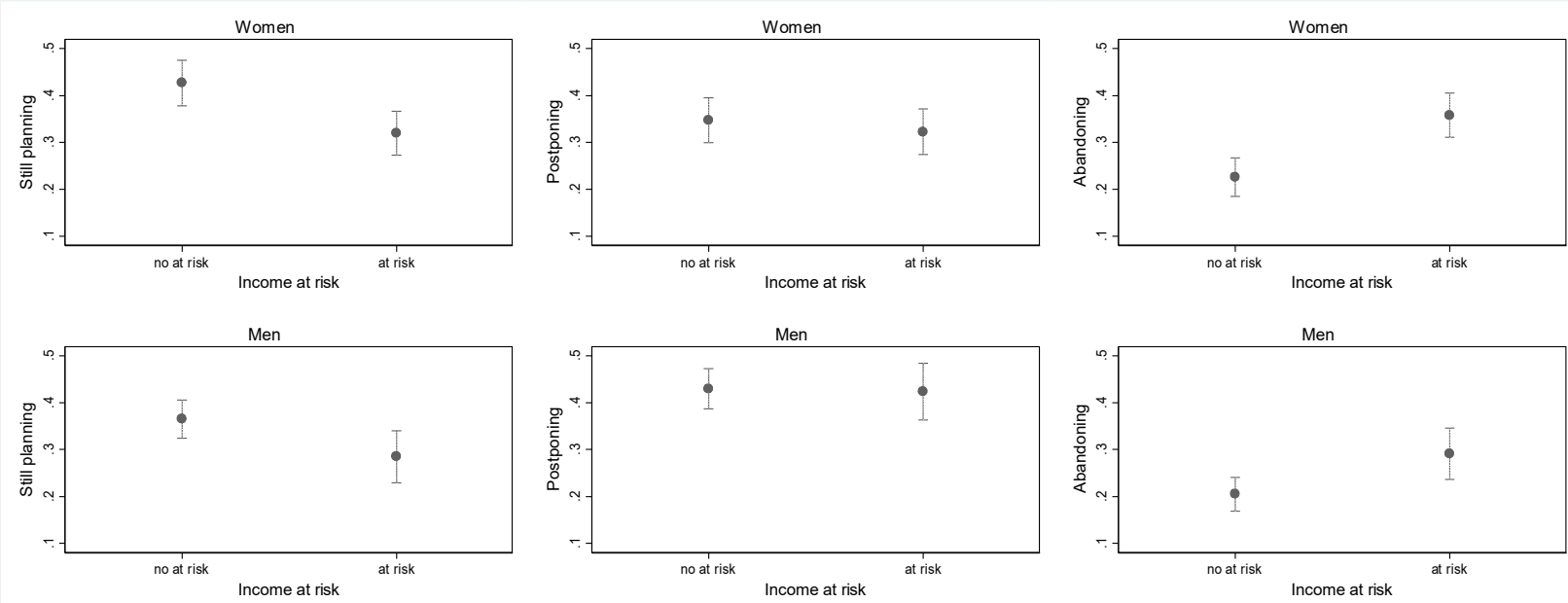

Note: Predicted probabilities bases on a multinomial logit model, controlling for age class, education, marital status, presence of children. Full results are available in Tables 4A and 5A in Supplementary Materials. Displayed confidence 
intervals allow having an average level of 5\% for the Type I error probability in the pair-wise comparisons of predicted values. No differences in terms of significancy has been found with confidence intervals at $10 \%$.

\section{Conclusion}

A wide interest on the consequences of the COVID-19 emergency on fertility has arisen worldwide in the scientific community since the beginning of the pandemic. Prediction about drops in births have been largely shared in the demographers' community (e.g., Lappegard et al. 2020, Lindberg et al. 2020, Luppi et al. 2020, Micelli et al. 2020, Ullah et al. 2020, Wilde et al. 2020) and preliminary data from birth statistics confirm a drop in the birth rates 8-9 months after the beginning of the health emergency in Italy (Blangiardo 2021), as well as in the US and several other European and Asian countries (Cohen 2021; Sobotka et al. 2021). In Italy, the very low fertility level was already a concern for demographers and policy makers before the pandemic. Hence, a possible further decline in fertility due to the COVID-19 health and economic crisis would posit new challenges to the holding of both the economic development and the welfare state in the medium term. This is particularly worrying given that the new COVID-related recession sums up in Italy to the effects of the 2008 Great Recession, further compromising the life plans of what has been called the "lost generation" (Bell and Blanchflower 2010).

Despite the great interest that fertility behaviours have traditionally attracted when exploring the demographic consequence of economic and health crises, fertility intentions are highly informative in the short-term, in part because changes in fertility behaviours need longer time to be detected, but also because by investigating the intentions it is possible to consider in which way people are revising their fertility plans (Testa and Basten 2014). In this study, fertility intentions have been examined in two alternative ways: 1) using the classical intention to conceive a child in the following 12 months, before and during the pandemic; 2) distinguishing confirmed, postponed or abandoned (i.e., indefinitely suspended) fertility plans for those who, before the pandemic, were planning to conceive a child in 2020. In particular, we were able to distinguish those who are postponing their pre-COVID plan from those who abandoned it. This is important because we may expect that postponers will more likely delay the childbirth to a next future, while for the abandoners both the scenarios of a long-term delay and of a withdrawal are plausible. This last group of individuals can be considered particularly vulnerable, as their fertility plans seem to be more easily compromised by the crisis. This interpretation is supported by our results, which show a 
clear association between higher levels of economic uncertainty and higher chances to abandon the fertility plan.

From a methodological point of view, using two alternative approaches to examine the effect of COVID-19 on fertility intentions have strengthened the validity of our findings. In fact, the two approaches differ not only with respect to the question used to assess fertility intentions but also with respect to the design of the analysis. More specifically, we exploited both independent samples drawn before (2016) and during the pandemic (2020; "regular waves") and retrospective information collected during the pandemic on pre-COVID fertility plans ("COVID waves" collected at the beginning of the health emergency in Italy - March 2020 - and before the adoption of the containment measures for the second wave of the epidemic - October 2020).

In Italy, occupational categories have been hit differently by the economic crisis, with selfemployed and temporary workers much more affected than employees, at least in the 2020 (Eurofound 2020).

Consistently with this, by comparing the short-term fertility intentions (within 12 months) among similar samples of young individuals in 2016 and 2020, we find that individuals with more vulnerable occupations show a lower probability of definitely intending to have a(nother) child soon. For self-employed and temporary workers, the changes in the fertility intentions between the two considered time points are considerable from a substantive point of view: from $16 \%$ to $3 \%$ for women, and from $17 \%$ to $5 \%$ for men. This indicates that, in periods of recession, fertility plans are more at risk for individuals who experience greater occupational uncertainty, and especially among women. This result contrasts the often reported finding that women invest more in childbearing during periods of economic uncertainty to substitute the loss of employment opportunities (Liefbroer and Corijn 1999, Andersson 2000, Adsera 2011, Vikat 2004, Gonzalez and Jurado 2006, Schmitt 2008). This might suggest an increasing similarity between women and men behaviours among the young generations. During the COVID-19 pandemic, in fact, among women the income effect (i.e., economic uncertainty inhibiting the demand for children) exceeds the substitution effect (i.e., economic uncertainty facilitating childbearing as unemployment increases the time for childcare). However, previous studies also show that the substitution effect prevails when the perceived employment and income fragility is perceived as a temporary condition; on the contrary, the income effect might be stronger when the perceived and experienced "unemployment trap" lasts longer (Adserà 2004, 2011, Bossert and D’Ambrosio 2013). Therefore, this might suggest a "scare- 
effect" (Schmitt 2012) of possible long-term negative consequences of the COVID-crisis on the youth labour market in Italy.

To understand the role of economic uncertainty brought by the COVID-19 pandemic and given that the COVID-19 pandemic is not egalitarian in its effects, we compared those who decided to indefinitely suspend their fertility plans as a consequence of the pandemic to those who postponed or confirmed the original fertility plan, by looking at both objective and subjective indicators of economic uncertainty. In particular, we found that individuals who are more vulnerable in terms of occupational and financial conditions are more prone to indefinitely suspend the plan to conceive a child in the short term. Working under unstable conditions or even not working, experiencing or expecting a drop in income, and perceiving occupation as at risk, are among the characteristics associated with a higher probability to abandon the fertility plans for the 2020. Consistently with results from other studies (Vignoli et al. 2020a), women more than men tend to abandon the fertility plans for the 2020 when they experience or perceive an occupational and income vulnerability. However, differences across occupational categories appear only for data collected at the beginning of the health emergency - in March 2020 - while in October of the same year such differences are no longer present. This suggests that, at least before the second pandemic wave, the impact of the crisis on fertility plans tends to become more homogeneous across occupational groups, while the specific individual economic conditions (having or not being economically affected by the crisis) and expectations are equally relevant in both periods as our findings show. For example, the probability of abandoning the pre-COVID fertility plan for women who expect the pandemic to produce a negative shock on their income in the future is $36 \%$ against $23 \%$ for those who do not hold such a negative expectation (for men: $29 \%$ vs $20 \%$ ).

The (qualitatively) different results we find for occupational status using the regular waves and the COVID-waves might also in part be related to the specific timing of the waves. The first COVIDwave was carried out in March 2020 during a strict lockdown where most shops and many economic activities were closed. Data for the second COVID-wave, instead, were collected in October after the relatively quiet summer, for what the pandemic dynamic is concerned, and in a period where more economic activities were operating compared to March. The regular 2020 wave was implemented in November, which can be considered both in terms of pandemic and economic conditions as in-between the March and October 2020 periods. Further studies, with longer periods of observation, might focus on the fertility intentions trends following the development of the health crisis, for example considering a possible impact of the vaccination campaign. 
A limitation of our data is that they are restricted to young individuals aged 18-34. Although this is one of the groups that most likely experienced the negative economic consequences of the pandemic in Italy (Arpino et al. 2020; Eurofound 2020), in case older individuals' objective or subjective economic circumstances have been affected the consequences on their fertility plans might be even stronger (Beaujouan et al. 2019). Additionally, because of the data constrain, we only focused on the negative impact of the pandemic on fertility plans; in other words, we did not consider those who did not have a plan to conceive a child in 2020 in the pre-pandemic period but changed their mind during the health emergency. Micelli and colleagues (2020) in fact, report a small but significant proportion of individuals who revealed a new desire for parenthood during the first lockdown (11.5\%), and the $4.3 \%$ of them also tried to conceive a child during that period because, for example, they were valuing more their family investment and the time spent with the partner/children. There might be some cases in which the teleworking opportunities spread by the epidemic had favoured the work-family reconciliation, even though the average net effect of the health emergency was detrimental on the work-family balance, especially on the women's side (Del Boca et al. 2020).

Despite the limitations, our findings have important policy implications. In periods of great uncertainty, such as the period during the COVID-19 pandemic and those that will follow it, exploring fertility intentions gives a great advantage to policy makers for reducing the potential negative impact of the crisis on fertility, especially in those countries where fertility decline was an issue even before the pandemic occurrence. Fertility realizations to be observed need longer time span, especially if we aim to find the characteristics associated with higher chances of postponement and withdrawal from the original fertility plans. For this reason, because fertility intentions in our study have been operationalized exactly as the intention to confirm, postpone or abandon the original fertility plan, we have a more precise idea on the level of vulnerability associated to the fertility plan as perceived by the individual. Our findings clearly point to the fact that the unequal economic consequences of the pandemic also produced and will produce heterogeneous effects on fertility. Policy makers who aim at contrasting the possibly persistent COVID shocks on fertility should implement labor market and family policies that allow the individuals to plan irreversible important childbearing choices with a less uncertain horizon. In this respect, the 2021 Italian universal child allowance (AUUF - “Assegno Unico e Universale per $i$ Figli") has been adopted with the aim of creating more favourable conditions for childbearing; the allowance supports the financial investment for rearing children from the $7^{\text {th }}$ month of pregnancy to 
21 years, it is only partially income-based (i.e., there is a minimum which is universally provided) and it increases with the second child. This income-support policy should represent the starting point of the implementation of the so-called "Family Act", which aims at improving policies and tools for work-family reconciliation and childcare services. This policy intervention follows a similar set of measures that have been adopted in Germany starting from 2012; at that time, despite the country had been marginally hit by the Great Recession and its economy and labour market were highly performant, the German fertility rate was among the lowest in Europe. The adoption of a universal allowance for children, together with the empowerment of the parental leave system and the childcare services, has strongly pushed fertility rate upwards (Bauernschuster et al. 2016). Because of the expected - and partially already experienced - negative effect of the COVID-19 recession on births in many developed countries, those countries that were already experiencing pre-pandemic downward fertility trends are now in the urgent need to create more favourable conditions for childbearing, avoiding that the postponement due to the recession would end into a further fertility decline. 


\section{References}

Aassve, A., Cavalli, N., Mencarini, L., Plach, S., \& Bacci, M. L. (2020). The COVID-19 pandemic and human fertility. Science, 369(6502), 370-371.

Adsera, A. (2004). Changing fertility rates in developed countries. The impact of labor market institutions. Journal of population economics, 17(1), 17-43.

Adsera, A., \& Menendez, A. (2011). Fertility changes in Latin America in periods of economic uncertainty. Population studies, 65(1), 37-56.

Adsera, A. (2011). Where are the babies? Labor market conditions and fertility in Europe. European Journal of Population/Revue européenne de Démographie, 27(1), 1-32.

Alderotti, G., Vignoli, D., Baccini, M., \& Matysiak, A. (2019). Employment uncertainty and fertility: A network meta-analysis of European research findings (No. 2019_06). Universita'degli Studi di Firenze, Dipartimento di Statistica, Informatica, Applicazioni" G. Parenti".

Ahn, N., \& Mira, P. (2002). A note on the changing relationship between fertility and female employment rates in developed countries. Journal of population Economics, 15(4), 667-682.

Amendola, S. (2021). Trends in rates of NEET (not in education, employment, or training) subgroups among youth aged 15 to 24 in Italy, 2004-2019. Journal of Public Health, 1-9.

Arpino, B., Esping-Andersen, G., \& Pessin, L. (2015). How do changes in gender role attitudes towards female employment influence fertility? A macro-level analysis. European Sociological Review, 31(3), 370-382.

Arpino, B., Pasqualini, M., Bordone, V., \& Solé-Auró, A. (2020, July 7). Indirect consequences of COVID-19 on people's lives. Findings from an on-line survey in France, Italy and Spain. https://doi.org/10.31235/osf.io/4sfv9

Arpino B, Pasqualini M, Bordone V, Solé A (2020) Older people's non-physical contacts and depression during the COVID-19 lockdown. The Gerontologist, doi: 10.1093/geront/gnaa144.

Baker, S. R., Bloom, N., Davis, S. J., \& Terry, S. J. (2020). Covid-induced economic uncertainty (No. w26983). National Bureau of Economic Research. 
Baizán, P. (2005, July). Couples' career and fertility. An event history analysis of the ECHP samples of Denmark, Italy, Spain and United Kingdom. In XXV International Population Conference, Tours, France.

Balzarini R, Muise A, ... Slatcher R (2020) Love in the Time of Covid: Perceived Partner Responsiveness Buffers People from Lower Relationship Quality Associated with Covid-Related Stressors. PsyArXiv e3fh4.

Barbieri, P., Bozzon, R., Scherer, S., Grotti, R., \& Lugo, M. (2015). The rise of a Latin model? Family and fertility consequences of employment instability in Italy and Spain. European societies, 17(4), 423-446.

Barbieri, P., \& Bozzon, R. (2016). Welfare, labour market deregulation and households' poverty risks: An analysis of the risk of entering poverty at childbirth in different European welfare clusters. Journal of European Social Policy, 26(2), 99-123.

Barbieri, P., \& Scherer, S. (2005). Le conseguenze sociali della flessibilizzazione del mercato del lavoro in Italia. Stato e mercato, 25(2), 291-322.

Bauernschuster, S., Hener, T., \& Rainer, H. (2016). Children of a (policy) revolution: The introduction of universal child care and its effect on fertility. Journal of the European Economic Association, 14(4), 975-1005.

Beaujouan, E. (2021). Covid-19 Global Demographic Research Needs? Replacing Speculative Commentaries with Robust Cross-national Comparisons. In MacKellar, L., \& Friedman, R. (eds). Covid-19 and the Global Demographic Research Agenda. New York: Population Council, 2021

Beaujouan, É., Reimondos, A., Gray, E., Evans, A., \& Sobotka, T. (2019). Declining realisation of reproductive intentions with age. Human Reproduction, 34(10), 1906-1914

Bell, D., \& Blanchflower, D. G. (2010, October). Young people and recession: A lost generation?. In Fifty-Second Panel Meeting on Economic Policy, Einaudi Institute for Economics and Finance, October (pp. 22-23).

Bellani D, Vignoli D (2020) Does love laugh at locksmiths? Partnership quality during the lockdown in Italy, France and Spain. Some descriptive findings. Cambio. Rivista sulle trasformazioni sociali. 
Benavides, F. G., Benach, J., Diez-Roux, A. V., \& Roman, C. (2000). How do types of employment relate to health indicators? Findings from the Second European Survey on Working Conditions. Journal of Epidemiology \& Community Health, 54(7), 494-501.

Bhaumik, S. K., \& Nugent, J. B. (2011). Real options and demographic decisions: empirical evidence from East and West Germany. Applied Economics, 43(21), 2739-2749.

Billari, F. C., Philipov, D., \& Testa, M. R. (2009). Attitudes, norms and perceived behavioural control: Explaining fertility intentions in Bulgaria. European Journal of Population, 25(4), 439465.

Blangiardo G.C. (2021) Primi riscontri e riflessioni sul bilancio demografico del 2020, ISTAT. Retrieved from: https://www.istat.it/it/files//2020/04/Riscontri-e-Riflessioni_Bilancio-demografico2020.pdf

Blasco-Belled, A., Tejada-Gallardo, C., Torrelles-Nadal, C., \& Alsinet, C. (2020). The costs of the COVID-19 on subjective well-being: an analysis of the outbreak in Spain. Sustainability, 12(15), 6243.

Blossfeld, H. P., \& Hofmeister, H. (Eds.). (2006). Globalization, uncertainty and women's careers: An international comparison. Edward Elgar Publishing.

Bossert, W., \& D'Ambrosio, C. (2013). Measuring economic insecurity. International Economic Review, 54(3), 1017-1030.

Brandolini, A., Casadio, P., Cipollone, P., Magnani, M., Rosolia, A., \& Torrini, R. (2007). Employment growth in Italy in the 1990s: institutional arrangements and market forces. In Social pacts, employment and growth (pp. 31-68). Physica-Verlag HD.

Brilli, Y., Kulic, N., \& Triventi, M. (2017). Who cares for the children? Family social position and childcare arrangements in Italy, 2002-12. In Childcare, Early Education and Social Inequality. Edward Elgar Publishing

Brzozowska, Z., \& Beaujouan, E. (2020). Assessing Short-Term Fertility Intentions and Their Realisation Using the Generations and Gender Survey: Pitfalls and Challenges. European Journal of Population, 1-12

Busetta, A., Mendola, D., \& Vignoli, D. (2019). Persistent joblessness and fertility intentions. Demographic Research, 40, 185-218 
Caltabiano, M., Comolli, C. L., \& Rosina, A. (2017). The effect of the Great Recession on permanent childlessness in Italy. Demographic Research, 37, 635-668.

Caltabiano, M., \& Rosina, A. (2018). The dejuvenation of the Italian population. Journal of Modern Italian Studies, 23(1), 24-40.

Chandra, S. and Yu, Y.L. (2015a). Fertility decline and the 1918 influenza pandemic in Taiwan. Biodemography and Social Biology 61(3): 266-272. doi:10.1080/19485565.2015.1062718.

Chandra, S. and Yu, Y.L. (2015b). The 1918 influenza pandemic and subsequent birth deficit in Japan. Demographic Research 33: 313-326. doi:10.4054/DemRes.2015.33.11.

Chandra, S., Christensen, J., Mamelund, S.E., and Paneth, N. (2018). Short-term birth sequelae of the 1918-1920 influenza pandemic in the United States: State-level analysis. American Journal of Epidemiology 187(12): 2585-2595. doi:10.1093/aje/kwy153.

Cherlin, A., Cumberworth, E., Morgan, S. P., \& Wimer, C. (2013). The effects of the Great Recession on family structure and fertility. The ANNALS of the American Academy of Political and Social Science, 650(1), 214-231.

Cohen, P. N. (2021, March 17). Baby Bust: Falling Fertility in US Counties Is Associated with COVID-19 Prevalence and Mobility Reductions. https://doi.org/10.31235/osf.io/qwxz3

Colussi T. (2020): IZA COVID-19 Crisis Response Monitoring: Italy (October 2020). Available at: https://www.iza.org/wc/files/downloads/iza_crisismonitor_countryreport_it_202010.pdf

Comolli, C. L., \& Bernardi, F. (2015). The causal effect of the great recession on childlessness of white American women. IZA Journal of Labor Economics, 4(1), 1-24.

Comolli, C. L. (2017). The fertility response to the Great Recession in Europe and the United States: Structural economic conditions and perceived economic uncertainty. Demographic research, 36, 1549-1600.

Comolli, C. L., Neyer, G., Andersson, G., Dommermuth, L., Fallesen, P., Jalovaara, M., ... \& Lappegård, T. (2020). Beyond the economic gaze: Childbearing during and after recessions in the Nordic countries. European Journal of Population, 1-48.

Comolli, C. L., \& Vignoli, D. (2021). Spreading Uncertainty, Shrinking Birth Rates: A Natural Experiment for Italy. European Sociological Review. 
Del Boca, D., \& Vuri, D. (2007). The mismatch between employment and child care in Italy: the impact of rationing. Journal of Population Economics, 20(4), 805-832.

Del Boca, D., Oggero, N., Profeta, P., \& Rossi, M. (2020). Women's and men's work, housework and childcare, before and during COVID-19. Review of Economics of the Household, 18(4), 10011017.

Donaldson, D., \& Keniston, D. (2014). How positive was the positive check? Investment and fertility in the aftermath of the 1918 influenza in India. Unpublished manuscript.( http://www. econ. yale. edu/ egcenter/Dave\% 20 Donaldson. pdf).

Drefahl S, Wallace M, Mussino E, ... Andersson G (2020) A population-based cohort study of socio-demographic risk factors for COVID-19 deaths in Sweden. Nature communications 11(1), 17.

Dupray, A., \& Pailhé, A. (2018). Does employment uncertainty particularly impact fertility of children of North African immigrants in France? A gender perspective. Journal of Ethnic and Migration Studies, 44(3), 401-424.

Emery, T., \& Koops, J. C. (2021, March 5). The Impact of COVID-19 on Fertility behaviour and Intentions in the Republic of Moldova. https://doi.org/10.31235/osf.io/fcqd9

Emmenegger, P., Häusermann, S., Palier, B., and Seeleib-Kaiser, M. (2012b). How rich countries cope with deindustrialization. In: Emmenegger, P., Häusermann, S., Palier, B., and Seeleib-Kaiser, M. (ed.). The age of dualization: The changing face of inequality in deindustrializing societies. Oxford: Oxford University Press: 304-320

Engelhardt, H., \& Prskawetz, A. (2004). On the changing correlation between fertility and female employment over space and time. European Journal of Population/Revue européenne de Démographie, 20(1), 35-62.

Eurofound (2020), Living, working and COVID-19, COVID-19 series, Publications Office of the European Union, Luxembourg

European Commission. (2019). 2019 Report on equality between women and men in the EU. https://ec.europa.eu/info/sites/info/files/aid_development_cooperation_fundamental_rights/annual_r eport_ge 2019 en.pdf 
Fahlén, S., \& Oláh, L. S. (2018). Economic uncertainty and first-birth intentions in Europe. Demographic Research, 39, 795-834.

Fiori, F., Graham, E., \& Rinesi, F. (2018). Economic reasons for not wanting a second child: Changes before and after the onset of the economic recession in Italy. Demographic research, 38 , 843-854.

Goldstein, J. R., Kreyenfeld, M., Jasilioniene, A., \& Örsal, D. K. (2013). Fertility reactions to the "Great Recession" in Europe: Recent evidence from order-specific data. Demographic research, 29, 85-104

González, M. J., \& Jurado-Guerrero, T. (2006). Remaining childless in affluent economies: a comparison of France, West Germany, Italy and Spain, 1994-2001 Rester sans enfant dans des sociétés d'abondances: une comparaison de la France, l'Allemagne de l'Ouest et l'Espagne, 199942001. European Journal of Population/Revue europeenne de demographie, 22(4), 317-352.

Guetto, R., Bazzani, G., \& Vignoli, D. (2020). Narratives of the future shape fertility in uncertain times. Evidence from the COVID-19 pandemic (No. 2020_11). Universita'degli Studi di Firenze, Dipartimento di Statistica, Informatica, Applicazioni" G. Parenti".

Hale, Thomas, Noam Angrist, Emily Cameron-Blake, Laura Hallas, Beatriz Kira, Saptarshi Majumdar, Anna Petherick, Toby Phillips, Helen Tatlow, Samuel Webster (2020). Oxford COVID19 Government Response Tracker, Blavatnik School of Government, University of Oxford

Ho FK, Petermann-Rocha, F... O'Donnell C (2020) Is older age associated with COVID-19 mortality in the absence of other risk factors? General population cohort study of 470,034 participants. PloS one 15(11), e0241824

Hofmeister, H., Blossfeld, H. P., \& Mills, M. (2006). Globalization, uncertainty and women's midcareer life courses: a theoretical framework. Globalization, uncertainty and women's careers: an international comparison, 3-31.

Hofmann, B., \& Hohmeyer, K. (2013). Perceived economic uncertainty and fertility: Evidence from a labor market reform. Journal of Marriage and Family, 75(2), 503-521.

Hofmann, B., Kreyenfeld, M., \& Uhlendorff, A. (2017). Job displacement and first birth over the business cycle. Demography, 54(3), 933-959. 
International Monetary Fund (2021). World Economic Outlook Reports. January 2021. Washington, DC: IMF. Available online at: https://www.imf.org/en/Publications/WEO/Issues/2021/01/26/2021-world-economic-outlookupdate

Istituto Nazionale di Statistica (ISTAT, 2021). Occupati e Disoccupati. Dicembre 2020 [Employed and Unemployed. December 2020], Roma: ISTAT. Available online at: https://www.istat.it/it/files//2021/02/Occupati-e-disoccupati_dicembre_2020.pdf

Kalleberg, A. L. (2009). Precarious work, insecure workers: Employment relations in transition. American sociological review, 74(1), 1-22.

Kearney M.S., \& Levine P.B. (2020). Half a million fewer children? The coming COVID baby bust. Retrieved from: https://www.brookings.edu/research/half-a-million-fewer-children-thecoming-covid-baby-bust/

Kiser, C. V., \& Whelpton, P. K. (1953). Resume of the Indianapolis study of social and psychological factors affecting fertility. Population Studies, 7(2), 95-110.

Kohler, H. P., Billari, F. C., \& Ortega, J. A. (2002). The emergence of lowest-low fertility in Europe during the 1990s. Population and development review, 28(4), 641-680.

Kreyenfeld, M. (2010). Uncertainties in female employment careers and the postponement of parenthood in Germany. European sociological review, 26(3), 351-366

Kreyenfeld, M., Andersson, G., \& Pailhé, A. (2012). Economic uncertainty and family dynamics in Europe. Introduction to Special Issue of Demographic Research,27(28), 835852. https://doi.org/10.4054/DemRes.2012.27.28.

Kreyenfeld, M. (2016). Economic uncertainty and fertility. In Social Demography Forschung an der Schnittstelle von Soziologie und Demografie (pp. 59-80). Springer VS, Wiesbaden.

Lambert, A., Cayouette-Remblière, J., Guéraut, É., Le Roux, G., Bonvalet, C., Girard, V., \& Langlois, L. (2020). How the COVID-19 epidemic changed working conditions in France. Population Societies, (7), 1-4.

Lappegård, T., Kristensen, A. P., \& Mamelund, S. E. (2020). Covid-19 could generate a baby 'bust'in the Nordic countries. LSE European Politics and Policy (EUROPP) blog 
Lesthaeghe, R. (2010). The unfolding story of the second demographic transition. Population and development review, 36(2), 211-251.

Liefbroer, A. C., \& Corijn, M. (1999). Who, what, where, and when? Specifying the impact of educational attainment and labour force participation on family formation. European Journal of Population/Revue Européenne de Démographie, 15(1), 45-75.

Lin, T. K., Law, R., Beaman, J., \& Foster, D. G. (2021). The impact of the COVID-19 pandemic on economic security and pregnancy intentions among people at risk of pregnancy. Contraception.

Lindberg, L. D., Vande Vusse, A., Mueller, J., \& Kirstein, M. (2020). Early impacts of the COVID19 pandemic: Findings from the 2020 Guttmacher Survey of Reproductive Health Experiences. New York, NY: Guttmacher Institute, 10(2020.31482).

Liotti, G. (2020). Labour market flexibility, economic crisis and youth unemployment in Italy. Structural Change and Economic Dynamics, 54, 150-162.

Lundström, K. E., \& Andersson, G. (2012). Labor market status, migrant status, and first childbearing in Sweden. Demographic Research, 27, 719-742.

Luppi, F., Arpino, B., \& Rosina, A. (2020). The impact of COVID-19 on fertility plans in Italy, Germany, France, Spain, and the United Kingdom. Demographic Research, 43, 1399-1412.

Luppi F., \& Rosina, A. (2020) Le conseguenze della pandemia sui progetti di vita dei giovani, In L'impatto della pandemia di COVID-19 su natalità e condizione delle nuove generazioni. Primo rapporto del gruppo di esperti "Demografia e COVID-19", Dipartimento per le politiche della famiglia, Presidenza del Consiglio dei Ministri. Retrieved from: http://famiglia.governo.it/media/2192/rapporto-gruppo-demografia-e-covid19 1412020.pdf

Luetke, M., Hensel, D., Herbenick, D., \& Rosenberg, M. (2020). Romantic relationship conflict due to the COVID-19 pandemic and changes in intimate and sexual behaviors in a nationally representative sample of American adults. Journal of Sex \& Marital Therapy, 46(8), 747-762.

Magnusson, K., Nygard, K. M., Vold, L., \& Telle, K. E. (2020). Occupational risk of COVID-19 in the 1st vs 2nd wave of infection. medRxiv.

Marteleto, L. J., Guedes, G., Coutinho, R. Z., \& Weitzman, A. (2020). Live births and fertility amid the Zika epidemic in Brazil. Demography, 57, 843-872. 
Mascherini, M., \& Ledermaier, S. (2016). Exploring the diversity of NEETs. Luxembourg: Publications Office of the European Union.

Matysiak, A., Sobotka, T., \& Vignoli, D. (2021). The Great Recession and fertility in Europe: A sub-national analysis. European Journal of Population, 37(1), 29-64

Micelli, E., Cito, G., Cocci, A., Polloni, G., Russo, G. I., Minervini, A., ... \& Coccia, M. E. (2020). Desire for parenthood at the time of COVID-19 pandemic: an insight into the Italian situation. Journal of Psychosomatic Obstetrics \& Gynecology, 41(3), 183-190.

Mills, M., Blossfeld, H. P., \& Klijzing, E. (2005). Becoming an adult in uncertain times. Globalization, uncertainty and youth in society: The losers in a globalizing world, 438.

Mills, M., \& Blossfeld, H. P. (2013). The second demographic transition meets globalization: A comprehensive theory to understand changes in family formation in an era of rising uncertainty. In Negotiating the life course (pp. 9-33). Springer, Dordrecht.

Modena, F., \& Sabatini, F. (2012). I would if i could: Precarious employment and childbearing intentions in Italy. Review of Economics of the Household, 10, 77-97

Modena F., C. Rondinelli, F. Sabatini (2013) Economic insecurity and fertility intentions: The case of Italy Review of Income and Wealth. Special Issue: Economic Insecurity: Challenges, Issues and Findings, 60 (S1)

Möhring, K., Naumann, E., Reifenscheid, M., Wenz, A., Rettig, T., Krieger, U., ... \& Blom, A. G. (2021). The COVID-19 pandemic and subjective well-being: longitudinal evidence on satisfaction with work and family. European Societies, 23(sup1), S601-S617.

Morgan, S. P., \& Bachrach, C. A. (2011). Is the Theory of Planned Behaviour an appropriate model for human fertility?. Vienna yearbook of population research, 9, 11-18.

Nasiri, M. J., Haddadi, S., Tahvildari, A., Farsi, Y., Arbabi, M., Hasanzadeh, S., ... \& Mirsaeidi, M. (2020). COVID-19 clinical characteristics, and sex-specific risk of mortality: Systematic Review and Meta-analysis. Frontiers in medicine, 7, 459.

Natale, F., Iacus, S. M., Conte, A., Spyratos, S., \& Sermi, F. (2021). Territorial differences in the spread of COVID-19 in European regions and US counties. arXiv preprint arXiv:2103.08321 
Novelli, M., Cazzola, A., Angeli, A., \& Pasquini, L. (2021). Fertility Intentions in Times of Rising Economic Uncertainty: Evidence from Italy from a Gender Perspective. Social Indicators Research, 154(1), 257-284.

Orgilés, M., Morales, A., Delvecchio, E., Mazzeschi, C., \& Espada, J. P. (2020). Immediate psychological effects of the COVID-19 quarantine in youth from Italy and Spain. Frontiers in psychology, 11, 2986

Pailhé, A. (2009). Work-family balance and childbearing intentions in France, Germany and the Russian Federation. Generations \& Gender Programme: How Generations and Gender Shape Demographic Change. Towards Policies Based on Better Knowledge. Geneva: United Nations, 5782.

Pailhé, A., \& Solaz, A. (2012). The influence of employment uncertainty on childbearing in France: A tempo or quantum effect?. Demographic research, 26, 1-40.

Palumbo, L., \& Sironi, E. (2016). A comparison of the determinants of childbearing intentions before and after the beginning of the economic crisis in Europe. Paper presented at the 3rd International ESS Conference, Lousanne. https://www.europeansocialsurvey.org. Retrived from 13-15 Jul 2016

Panzeri, M., Ferrucci, R., Cozza, A., \& Fontanesi, L. (2020). Changes in sexuality and quality of couple relationship during the Covid-19 lockdown. Frontiers in psychology, 11.

Pirani, E. (2017). On the relationship between atypical work (s) and mental health: New insights from the Italian case. Social Indicators Research, 130(1), 233-252.

Plümper, T., \& Neumayer, E. (2020). Lockdown policies and the dynamics of the first wave of the Sars-CoV-2 pandemic in Europe. Journal of European Public Policy, 1-21

Régnier-Loilier, A., \& Vignoli, D. (2011). Fertility intentions and obstacles to their realization in France and Italy. Population-E, 66(2), 361-390

Reichelt, M., Makovi, K., \& Sargsyan, A. (2020). The impact of COVID-19 on gender inequality in the labor market and gender-role attitudes. European Societies, 1-18.

Rindfuss, R. B., Morgan, S. P., \& Swicegood, G. (1988). First births in America. Changes in the timing of parenthood. Berkeley: University of California Press 
Rindfuss, R. R., Guzzo, K. B., \& Morgan, S. P. (2003). The changing institutional context of low fertility. Population Research and Policy Review, 22(5), 411-438.

Rondinelli, C., Aassve, A., \& Billari, F. C. (2010). Women's wages and childbearing decisions: Evidence from Italy. Demographic research, 22, 549-578.

Salvini, S. M., Pasqual, S., \& Vignoli, D. (2009). Strategie lavorative e intenzioni riproduttive di uomini e donne in coppia: uno sguardo alla situazione italiana (No. 8). Working Paper, Dipartimento di Statistica dell’Università di Firenze.

Schmitt, C. (2008). Gender-specific effects of unemployment on family formation: a cross-national perspective (No. 127). SOEPpapers on Multidisciplinary Panel Data Research.

Schmitt, C. (2012). Labour market integration, occupational uncertainties, and fertility choices in Germany and the UK. Demographic Research, 26, 253-292.

Schmitt, C. (2021). The impact of economic uncertainty, precarious employment, and risk attitudes on the transition to parenthood. Advances in Life Course Research, 47, 100402.

Schneider, D. (2015). The great recession, fertility, and uncertainty: Evidence from the United States. Journal of Marriage and Family, 77(5), 1144-1156.

Schoen, R., Astone, N. M., Kim, Y. J., Nathanson, C. A., \& Fields, J. M. (1999). Do fertility intentions affect fertility behavior? Journal of Marriage and Family, 61(3), 790-799

Sobotka, T. (2003). Tempo-quantum and period-cohort interplay in fertility changes in Europe. Evidence from the Czech Republic, Italy, the Netherlands and Sweden. Demographic research, 8, 151-214.

Sobotka, T., Skirbekk, V., \& Philipov, D. (2011). Economic recession and fertility in the developed world. Population and development review, 37(2), 267-306

Sobotka, T., Jasilioniene, A., Galarza, A. A., Zeman, K., Nemeth, L., \& Jdanov, D. (2021, March 24). Baby bust in the wake of the COVID-19 pandemic? First results from the new STFF data series. https://doi.org/10.31235/osf.io/mvy62

Stone L. (2020). Will the coronavirus spike births? (Institute for Family Studies, March 11, 2020) https://ifstudies.org/blog/will-the-coronavirus-spike-births 
Testa, M. R., \& Basten, S. (2014). Certainty of meeting fertility intentions declines in Europe during the 'Great Recession.' Demographic Research, 31(23), 687-734.

Trinitapoli, J., \& Yeatman, S. (2011). Uncertainty and fertility in a generalized AIDS epidemic. American Sociological Review, 76(6), 935-954.

Ullah, M. A., Moin, A. T., Araf, Y., Bhuiyan, A. R., Griffiths, M. D., \& Gozal, D. (2020). Potential Effects of the COVID-19 Pandemic on Future Birth Rate. Frontiers in Public Health, 8.

van der Wielen, W., \& Barrios, S. (2020). Fear and Employment During the COVID Pandemic: Evidence from Search Behaviour in the EU. JRC Working Paper on Taxation and Structural Reforms No 08/2020.

Vikat, A. (2004). Women's labor force attachment and childbearing in Finland. Demographic Research, 3, 177-212.

Vignoli, D., Drefahl, S., \& De Santis, G. (2012). Whose job instability affects the likelihood of becoming a parent in Italy? A tale of two partners. Demographic Research, 26, 41-62.

Vignoli D, Ciccarelli A., and Fabrizi E. (2019) Labour market circumstances and fertility in Italy: a first glance through ADSILC data, Rivista Italiana di Economia Demografia e Statistica, 73(4), 1728

Vignoli, D., Tocchioni, V., \& Mattei, A. (2020a). The impact of job uncertainty on first-birth postponement. Advances in Life Course Research, 45, 100308.

Vignoli, D., Guetto, R., Bazzani, G., Pirani, E. and Minello, A. (2020b). A reflection on economic uncertainty and fertility in Europe: the narrative framework. Genus, 76(1), pp. 1-27.

Vrachnis, N., Vlachadis, N., Iliodromiti, Z., Vlachadi, M., \& Creatsas, G. (2014). Greece's birth rates and the economic crisis. The Lancet, 383(9918), 692-693.

Wilde, J., Chen, W., \& Lohmann, S. (2020). COVID-19 and the future of US fertility: what can we learn from Google? (No. 13776). IZA Discussion Papers.

Witte, J. C., \& Wagner, G. G. (1995). Declining fertility in East Germany after unification: A demographic response to socioeconomic change. Population and development review, 387-397. 
Zacher, H., \& Rudolph, C. W. (2020). Individual differences and changes in subjective wellbeing during the early stages of the COVID-19 pandemic. American Psychologist.

Zhu, C., Wu, J., Liang, Y., Yan, L., He, C., Chen, L., \& Zhang, J. (2020). Fertility intentions among couples in Shanghai under COVID-19: A cross-sectional study. International Journal of Gynecology \& Obstetrics, 151(3), 399-406. 


\section{Supplementary Materials}

Table 1A Distribution of the main covariates and control variables for the regular waves (2016 and 2020); separated and pooled samples.

\begin{tabular}{|c|c|c|c|}
\hline & \multicolumn{3}{|c|}{ Regular waves } \\
\hline & 2016 & 2020 & Pooled \\
\hline \multicolumn{4}{|l|}{ Occupational status } \\
\hline NEET & $24.47 \%$ & $21.79 \%$ & $23.13 \%$ \\
\hline Professionals/employee & $65.58 \%$ & $66.76 \%$ & $66.17 \%$ \\
\hline Self employed/temporary workers & $9.95 \%$ & $11.45 \%$ & $10.70 \%$ \\
\hline Women & $55.17 \%$ & $57.13 \%$ & $56.15 \%$ \\
\hline \multicolumn{4}{|l|}{ Age class } \\
\hline $18-24$ & $8.44 \%$ & $9.10 \%$ & $8.77 \%$ \\
\hline $25-29$ & $33.21 \%$ & $32.45 \%$ & $32.83 \%$ \\
\hline $30-34$ & $58.35 \%$ & $58.44 \%$ & $58.40 \%$ \\
\hline Tertiary education & $22.57 \%$ & $24.45 \%$ & $23.50 \%$ \\
\hline Cohabiting/married & $35.85 \%$ & $45.62 \%$ & $40.72 \%$ \\
\hline With children & $25.74 \%$ & $27.24 \%$ & $26.49 \%$ \\
\hline Sample size & 1819 & 1467 & 3286 \\
\hline
\end{tabular}


Table 2A. Distribution of the main covariates and control variables for the COVID waves (March and October 2020); separated and pooled samples.

\begin{tabular}{|c|c|c|c|}
\hline & \multicolumn{3}{|c|}{ COVID waves } \\
\hline & March & October & Pooled \\
\hline \multicolumn{4}{|l|}{ Occupational status } \\
\hline NEET & $23.60 \%$ & $12.80 \%$ & $18.80 \%$ \\
\hline Professionals/employee & $62.00 \%$ & $71.80 \%$ & $66.41 \%$ \\
\hline Self employed/temporary workers & $14.40 \%$ & $15.40 \%$ & $14.79 \%$ \\
\hline Financial situation has worsened (a) & $50.84 \%$ & $29.33 \%$ & $41.48 \%$ \\
\hline Perceived income at risk (b) & $51.32 \%$ & $24.17 \%$ & $39.51 \%$ \\
\hline Perceived occupation at risk (b) & $54.79 \%$ & $73.16 \%$ & $62.78 \%$ \\
\hline Women & $49.10 \%$ & $53.30 \%$ & $51.00 \%$ \\
\hline \multicolumn{4}{|l|}{ Age class } \\
\hline $18-24$ & $21.28 \%$ & $18.56 \%$ & $20.09 \%$ \\
\hline $25-29$ & $27.10 \%$ & $27.43 \%$ & $27.24 \%$ \\
\hline $30-34$ & $51.60 \%$ & $54.01 \%$ & $52.66 \%$ \\
\hline Tertiary education & $23.98 \%$ & $18.83 \%$ & $21.74 \%$ \\
\hline Cohabiting/married & $48.01 \%$ & $53.12 \%$ & $50.23 \%$ \\
\hline With children & $27.38 \%$ & $40.62 \%$ & $33.14 \%$ \\
\hline Sample size & 445 & 313 & 758 \\
\hline
\end{tabular}

(a) "Compared to before the coronavirus emergency, your financial situation today: [1] has worsened a lot; [2] has slightly worsened; [3] nothing has changed; [4] has slightly improved; [5] has improved a lot". The variable has been dichotomized taking value 1 in the case the respondent reports their financial situation as worsened and 0 otherwise.

(b) "Thinking about your future, do you think the current coronavirus emergency will have a positive or negative impact on: your (personal) income / your occupation?" on a scale scoring from 1 (much negative) to 5 (much positive). The variable has been dichotomized, taking value 0 if the respondent expects a positive effect or null effect (values 3, 4 and 5), and value 1 in case the respondent is expecting negative returns in terms of income /occupation (values 1 and 2). 
Table 3A. Ordered logit model for the fertility intentions at 12 months, by gender (Regular waves, 2016 and 2020)

\begin{tabular}{|c|c|c|c|c|}
\hline & \multicolumn{2}{|c|}{ Women } & \multicolumn{2}{|c|}{ Men } \\
\hline & Coef. & p-value & Coef. & p-value \\
\hline \multicolumn{5}{|l|}{ Surely not } \\
\hline \multicolumn{5}{|l|}{ Age class (ref. 18-24) } \\
\hline $18-24$ & -0.710 & 0.016 & -0.111 & 0.817 \\
\hline $30-34$ & 0.708 & 0.000 & 0.691 & 0.011 \\
\hline Tertiary education & -0.435 & 0.001 & -0.022 & 0.913 \\
\hline \multicolumn{5}{|l|}{ Occupational status (ref. Employees) } \\
\hline NEET & -0.007 & 0.977 & -0.053 & 0.920 \\
\hline self-employed \& temporary & 0.622 & 0.059 & 0.741 & 0.221 \\
\hline \multicolumn{5}{|l|}{ Wave (ref. 2016) } \\
\hline 2020 & 0.183 & 0.363 & 0.401 & 0.155 \\
\hline \multicolumn{5}{|l|}{ Occupational status\#wave } \\
\hline NEET\#2020 & -0.290 & 0.465 & 0.241 & 0.759 \\
\hline self-employed \& temporary $\# 2020$ & -0.399 & 0.394 & -0.142 & 0.855 \\
\hline Married/cohabiting & 0.982 & 0.000 & 1.417 & 0.005 \\
\hline With children & -0.139 & 0.519 & -0.101 & 0.842 \\
\hline Constant & 0.241 & 0.414 & 0.148 & 0.761 \\
\hline \multicolumn{5}{|l|}{ Probably not } \\
\hline \multicolumn{5}{|l|}{ Age class (ref. 18-24) } \\
\hline $18-24$ & -0.224 & 0.462 & -0.661 & 0.174 \\
\hline $30-34$ & 0.526 & 0.000 & 0.477 & 0.056 \\
\hline Tertiary education & -0.384 & 0.001 & -0.100 & 0.540 \\
\hline \multicolumn{5}{|l|}{ Occupational status (ref. Employees) } \\
\hline NEET & 0.040 & 0.842 & 0.030 & 0.957 \\
\hline self-employed \& temporary & 0.218 & 0.594 & 1.000 & 0.093 \\
\hline \multicolumn{5}{|l|}{ Wave (ref. 2016) } \\
\hline 2020 & 0.162 & 0.306 & 0.204 & 0.356 \\
\hline \multicolumn{5}{|l|}{ Occupational status\#wave } \\
\hline NEET\#2020 & -0.462 & 0.159 & 0.423 & 0.566 \\
\hline self-employed \& temporary\#2020 & -0.651 & 0.227 & -0.468 & 0.527 \\
\hline Married/cohabiting & 0.878 & 0.000 & 1.153 & 0.000 \\
\hline With children & 0.117 & 0.484 & 0.198 & 0.460 \\
\hline Constant & -1.160 & 0.000 & -2.128 & 0.000 \\
\hline
\end{tabular}


Age class (ref. 18-24)

18-24

30-34

\begin{tabular}{ll|ll}
-0.059 & 0.908 & -1.148 & 0.199 \\
0.322 & 0.164 & 0.711 & 0.101 \\
-0.443 & 0.009 & 0.230 & 0.471 \\
& & & \\
0.143 & 0.636 & -0.371 & 0.746 \\
0.510 & 0.286 & 1.663 & 0.024 \\
& & & \\
0.501 & 0.026 & 0.220 & 0.573 \\
& & & \\
-0.945 & 0.067 & 0.758 & 0.589 \\
-2.424 & 0.001 & -1.761 & 0.065 \\
0.928 & 0.000 & 1.573 & 0.000 \\
-0.194 & 0.370 & -0.396 & 0.326 \\
-2.686 & 0.000 & -5.658 & 0.000 \\
\hline
\end{tabular}


Table 4A. Multinomial models for the intention of still-planning, postponing or abandoning the pre-pandemic fertility plan, for women (COVID waves, March and October 2020)

\begin{tabular}{|c|c|c|c|c|c|c|c|c|}
\hline & \multicolumn{2}{|c|}{ Model 1} & \multicolumn{2}{|c|}{ Model 2} & \multicolumn{2}{|c|}{ Model 3} & \multicolumn{2}{|c|}{ Model 4} \\
\hline & Coeff & p-value & Coeff & p-value & Coeff & p-value & Coeff & p-value \\
\hline \multicolumn{9}{|l|}{ still-planning (ref) } \\
\hline \multicolumn{9}{|l|}{ postponing } \\
\hline \multicolumn{9}{|l|}{ Age class } \\
\hline $18-24$ & -0.075 & 0.862 & -0.075 & 0.862 & -0.055 & 0.898 & -0.046 & 0.916 \\
\hline $30-34$ & -0.397 & 0.174 & -0.402 & 0.169 & -0.418 & 0.153 & -0.437 & 0.137 \\
\hline Tertiary education & 0.203 & 0.464 & 0.194 & 0.486 & 0.235 & 0.392 & 0.242 & 0.377 \\
\hline Married/cohabiting & -0.410 & 0.152 & -0.426 & 0.138 & -0.425 & 0.136 & -0.434 & 0.130 \\
\hline With children & -0.379 & 0.174 & -0.379 & 0.174 & -0.366 & 0.188 & -0.366 & 0.190 \\
\hline October 2020 (ref. March 2020) & -0.394 & 0.136 & -0.403 & 0.127 & -0.348 & 0.193 & -0.340 & 0.204 \\
\hline High spread SARS-CoV-2 region & -0.109 & 0.677 & -0.101 & 0.701 & -0.106 & 0.686 & -0.102 & 0.697 \\
\hline \multicolumn{9}{|l|}{ Occupational status (ref. Employees) } \\
\hline NEET & -0.012 & 0.971 & 0.008 & 0.980 & 0.005 & 0.988 & 0.009 & 0.977 \\
\hline self \& temporary & 0.083 & 0.840 & 0.035 & 0.932 & 0.112 & 0.783 & 0.103 & 0.838 \\
\hline Occupation at risk & & & 0.234 & 0.362 & & & & \\
\hline Financial condition already worsen & & & & & 0.192 & 0.461 & & \\
\hline Income at risk & & & & & & & 0.258 & 0.328 \\
\hline Constant & 1.082 & 0.039 & 0.975 & 0.069 & 0.871 & 0.099 & 0.918 & 0.095 \\
\hline \multicolumn{9}{|l|}{ abandoning } \\
\hline \multicolumn{9}{|l|}{ Age class } \\
\hline $18-24$ & 0.036 & 0.935 & 0.028 & 0.950 & 0.124 & 0.781 & 0.168 & 0.709 \\
\hline $30-34$ & -0.565 & 0.071 & -0.576 & 0.067 & -0.702 & 0.027 & -0.668 & 0.036 \\
\hline Tertiary education & -0.645 & 0.045 & -0.645 & 0.045 & -0.477 & 0.075 & -0.577 & 0.075 \\
\hline Married/cohabiting & -0.632 & 0.041 & -0.677 & 0.030 & -0.739 & 0.019 & -0.702 & 0.026 \\
\hline With children & -0.337 & 0.276 & -0.325 & 0.296 & -0.264 & 0.399 & -0.321 & 0.306 \\
\hline October 2020 (ref. March 2020) & -0.975 & 0.001 & -1.024 & 0.001 & -0.752 & 0.012 & -0.823 & 0.006 \\
\hline High spread SARS-CoV-2 region & -0.604 & 0.038 & -0.599 & 0.041 & -0.658 & 0.027 & -0.626 & 0.034 \\
\hline \multicolumn{9}{|l|}{ Occupational status (ref. Employees) } \\
\hline NEET & 0.326 & 0.325 & 0.376 & 0.260 & 0.470 & 0.150 & 0.317 & 0.343 \\
\hline self \& temporary & 0.337 & 0.439 & 0.237 & 0.590 & 0.458 & 0.295 & 0.282 & 0.525 \\
\hline Occupation at risk & & & 0.581 & 0.042 & & & & \\
\hline Financial condition already worsen & & & & & 0.962 & 0.001 & & \\
\hline Income at risk & & & & & & & 0.850 & 0.004 \\
\hline Constant & 2.255 & 0.000 & 1.998 & 0.000 & 1.152 & 0.041 & 1.669 & 0.005 \\
\hline
\end{tabular}


Table 5A. Multinomial models for the intention of still-planning, postponing or abandoning the pre-pandemic fertility plan, for men (COVID waves, March and October 2020)

\begin{tabular}{|c|c|c|c|c|c|c|c|c|}
\hline & \multicolumn{2}{|c|}{ Model 1} & \multicolumn{2}{|c|}{ Model 2} & \multicolumn{2}{|c|}{ Model 3} & \multicolumn{2}{|c|}{ Model 4} \\
\hline & Coeff & p-value & Coeff & p-value & Coeff & p-value & Coeff & p-value \\
\hline \multicolumn{9}{|l|}{ still-planning (ref) } \\
\hline \multicolumn{9}{|l|}{ postponing } \\
\hline \multicolumn{9}{|l|}{ Age class } \\
\hline $18-24$ & 0.176 & 0.639 & 0.178 & 0.635 & 0.178 & 0.635 & 0.204 & 0.587 \\
\hline $30-34$ & -0.281 & 0.374 & -0.275 & 0.385 & -0.255 & 0.418 & -0.282 & 0.372 \\
\hline Tertiary education & -0.037 & 0.883 & -0.038 & 0.879 & -0.042 & 0.868 & -0.023 & 0.928 \\
\hline Married/cohabiting & -0.742 & 0.009 & -0.742 & 0.009 & -0.744 & 0.009 & -0.703 & 0.015 \\
\hline With children & -0.358 & 0.241 & -0.357 & 0.243 & -0.342 & 0.259 & -0.392 & 0.203 \\
\hline October 2020 (ref. March 2020) & -0.491 & 0.059 & -0.481 & 0.069 & -0.485 & 0.063 & -0.436 & 0.101 \\
\hline High spread SARS-CoV-2 region & 0.136 & 0.600 & 0.137 & 0.599 & 0.135 & 0.603 & 0.141 & 0.588 \\
\hline \multicolumn{9}{|l|}{ Occupational status (ref. Employees) } \\
\hline NEET & -0.014 & 0.973 & -0.003 & 0.994 & -0.046 & 0.913 & -0.022 & 0.959 \\
\hline self \& temporary & 0.559 & 0.141 & 0.561 & 0.140 & 0.579 & 0.127 & 0.553 & 0.147 \\
\hline Occupation at risk & & & -0.049 & 0.849 & & & & \\
\hline Financial condition already worsen & & & & & 0.011 & 0.968 & & \\
\hline Income at risk & & & & & & & 0.268 & 0.336 \\
\hline Constant & 1.389 & 0.003 & 1.399 & 0.003 & 1.416 & 0.003 & 1.213 & 0.016 \\
\hline \multicolumn{9}{|l|}{ abandoning } \\
\hline \multicolumn{9}{|l|}{ Age class } \\
\hline $18-24$ & -0.287 & 0.523 & -0.291 & 0.518 & -0.312 & 0.488 & -0.245 & 0.588 \\
\hline $30-34$ & -0.198 & 0.590 & -0.218 & 0.554 & -0.259 & 0.481 & -0.231 & 0.530 \\
\hline Tertiary education & -0.265 & 0.377 & -0.251 & 0.405 & -0.208 & 0.493 & -0.232 & 0.443 \\
\hline Married/cohabiting & -0.340 & 0.302 & -0.344 & 0.297 & -0.349 & 0.289 & -0.237 & 0.480 \\
\hline With children & -0.551 & 0.131 & -0.543 & 0.135 & -0.490 & 0.178 & -0.646 & 0.081 \\
\hline October 2020 (ref. March 2020) & -1.071 & 0.001 & -1.117 & 0.001 & -1.013 & 0.002 & -0.929 & 0.005 \\
\hline High spread SARS-CoV-2 region & 0.185 & 0.545 & 0.184 & 0.547 & 0.203 & 0.507 & 0.201 & 0.513 \\
\hline \multicolumn{9}{|l|}{ Occupational status (ref. Employees) } \\
\hline NEET & 0.149 & 0.760 & & & 0.067 & 0.890 & 0.102 & 0.836 \\
\hline self \& temporary & 1.303 & 0.001 & & & 1.342 & 0.001 & 1.284 & 0.002 \\
\hline Occupation at risk & & & 0.233 & 0.443 & & & & \\
\hline Financial condition already worsen & & & & & 0.540 & 0.082 & & \\
\hline Income at risk & & & & & & & 0.655 & 0.039 \\
\hline Constant & 1.411 & 0.010 & 1.345 & 0.015 & 1.214 & 0.030 & 0.966 & 0.101 \\
\hline
\end{tabular}


Table 6A. Multinomial models for the intention of still-planning, postponing or abandoning the pre-pandemic fertility plan with survey wave as mediator, for women (COVID waves, March and October 2020)

\begin{tabular}{|c|c|c|c|c|c|c|c|c|}
\hline & \multicolumn{2}{|c|}{ Model 1} & \multicolumn{2}{|c|}{ Model 2} & \multicolumn{2}{|c|}{ Model 3} & \multicolumn{2}{|c|}{ Model 4} \\
\hline & Coeff. & p-value & Coeff. & p-value & Coeff. & p-value & Coeff. & p-value \\
\hline \multicolumn{9}{|l|}{ Still-planning } \\
\hline \multicolumn{9}{|l|}{ Postponing } \\
\hline \multicolumn{9}{|l|}{ Age class } \\
\hline $18-24$ & -0.045 & 0.917 & -0.084 & 0.847 & -0.019 & 0.965 & -0.071 & 0.870 \\
\hline $30-34$ & -0.393 & 0.179 & -0.419 & 0.154 & -0.435 & 0.140 & -0.394 & 0.178 \\
\hline Tertiary education & 0.186 & 0.505 & 0.216 & 0.440 & 0.220 & 0.432 & 0.189 & 0.496 \\
\hline Married/cohabiting & -0.412 & 0.153 & -0.404 & 0.159 & -0.430 & 0.135 & -0.418 & 0.146 \\
\hline With children & -0.386 & 0.169 & -0.371 & 0.183 & -0.368 & 0.189 & -0.379 & 0.173 \\
\hline High spread COVID-19 region & -0.116 & 0.661 & -0.089 & 0.735 & -0.098 & 0.709 & -0.090 & 0.733 \\
\hline \multicolumn{9}{|l|}{ Occupational status } \\
\hline NEET & 0.294 & 0.491 & -0.035 & 0.916 & -0.033 & 0.922 & 0.001 & 0.997 \\
\hline self \& temporary & 0.682 & 0.303 & 0.093 & 0.820 & 0.076 & 0.853 & 0.034 & 0.934 \\
\hline October 2020 (ref. March 2020) & -0.155 & 0.619 & & & & & & \\
\hline NEET*wave & -0.667 & 0.306 & & & & & & \\
\hline self \& temporary*wave & -0.974 & 0.252 & & & & & & \\
\hline $\begin{array}{l}\text { Financial condition already } \\
\text { worsen }\end{array}$ & & & -0.107 & 0.767 & & & & \\
\hline October 2020 (ref. March 2020) & & & -0.630 & 0.079 & & & & \\
\hline Worse financial condition*wave & & & 0.602 & 0.244 & & & & \\
\hline Income at risk & & & & & 0.005 & 0.988 & & \\
\hline October 2020 (ref. March 2020) & & & & & -0.562 & 0.111 & & \\
\hline Income at risk ${ }^{*}$ wave & & & & & 0.493 & 0.346 & & \\
\hline Occupation at risk & & & & & & & 0.127 & 0.723 \\
\hline October 2020 (ref. March 2020) & & & & & & & -0.563 & 0.161 \\
\hline Occupation at risk ${ }^{*}$ wave & & & & & & & 0.258 & 0.619 \\
\hline Constant & 0.567 & 0.137 & 0.859 & 0.055 & 1.124 & 0.010 & 0.620 & 0.130 \\
\hline \multicolumn{9}{|l|}{ Abandoning } \\
\hline \multicolumn{9}{|l|}{ Age class } \\
\hline $18-24$ & 0.075 & 0.868 & 0.169 & 0.708 & 0.213 & 0.641 & 0.007 & 0.987 \\
\hline $30-34$ & -0.574 & 0.069 & -0.661 & 0.039 & -0.685 & 0.033 & -0.584 & 0.064 \\
\hline Tertiary education & -0.677 & 0.037 & -0.581 & 0.076 & -0.587 & 0.073 & -0.632 & 0.050 \\
\hline Married/cohabiting & -0.630 & 0.046 & -0.711 & 0.025 & -0.715 & 0.024 & -0.697 & 0.027 \\
\hline With children & -0.355 & 0.259 & -0.267 & 0.400 & -0.300 & 0.341 & -0.313 & 0.315 \\
\hline High spread COVID-19 region & -0.590 & 0.044 & -0.647 & 0.029 & -0.609 & 0.039 & -0.623 & 0.034 \\
\hline
\end{tabular}


Occupational status

NEET

self \& temporary

October 2020 (ref. March 2020)

NEET*wave

self \& temporary*wave

Financial condition already

worsen

October 2020 (ref. March 2020)

Worse financial condition*wave

Income at risk

October 2020 (ref. March 2020)

Income at risk*wave

Occupation at risk

October 2020 (ref. March 2020)

Occupation at risk*wave

\begin{tabular}{|c|c|c|c|c|c|c|c|}
\hline 0.797 & 0.051 & 0.302 & 0.367 & 0.301 & 0.369 & 0.386 & 0.250 \\
\hline 1.168 & 0.071 & 0.297 & 0.507 & 0.272 & 0.543 & 0.230 & 0.602 \\
\hline-0.446 & 0.216 & & & & & & \\
\hline-1.385 & 0.055 & & & & & & \\
\hline-1.789 & 0.064 & & & & & & \\
\hline & & 0.765 & 0.044 & & & & \\
\hline & & -1.078 & 0.015 & & & & \\
\hline & & 0.500 & 0.397 & & & & \\
\hline & & & & 0.394 & 0.280 & & \\
\hline & & & & -1.433 & 0.001 & & \\
\hline & & & & 1.210 & 0.040 & & \\
\hline & & & & & & 0.759 & 0.037 \\
\hline & & & & & & -0.630 & 0.172 \\
\hline & & & & & & -0.608 & 0.302 \\
\hline 1.058 & 0.007 & 0.859 & 0.055 & 1.124 & 0.010 & 0.884 & 0.039 \\
\hline
\end{tabular}


Table 7A. Multinomial models for the intention of still-planning, postponing or abandoning the pre-pandemic fertility plan with survey wave as mediator, for men (COVID waves, March and October 2020)

\begin{tabular}{|c|c|c|c|c|c|c|c|c|}
\hline & \multicolumn{2}{|c|}{ Model 1} & \multicolumn{2}{|c|}{ Model 2} & \multicolumn{2}{|c|}{ Model 3} & \multicolumn{2}{|c|}{ Model 4} \\
\hline & Coeff. & p-value & Coeff. & p-value & Coeff. & p-value & Coeff. & p-value \\
\hline \multicolumn{9}{|l|}{ Still-planning } \\
\hline \multicolumn{9}{|l|}{ Postponing } \\
\hline \multicolumn{9}{|l|}{ Age class } \\
\hline $18-24$ & 0.203 & 0.590 & 0.178 & 0.634 & 0.207 & 0.582 & 0.137 & 0.716 \\
\hline $30-34$ & -0.258 & 0.414 & -0.298 & 0.350 & -0.288 & 0.363 & -0.306 & 0.337 \\
\hline Tertiary education & -0.051 & 0.841 & -0.026 & 0.918 & -0.015 & 0.953 & -0.016 & 0.950 \\
\hline Married/cohabiting & -0.765 & 0.008 & -0.743 & 0.010 & -0.707 & 0.015 & -0.758 & 0.008 \\
\hline With children & -0.371 & 0.226 & -0.356 & 0.246 & -0.389 & 0.206 & -0.319 & 0.300 \\
\hline High spread COVID-19 region & 0.134 & 0.608 & 0.146 & 0.577 & 0.145 & 0.578 & 0.158 & 0.545 \\
\hline \multicolumn{9}{|l|}{ Occupational status } \\
\hline NEET & 0.271 & 0.616 & -0.039 & 0.926 & -0.029 & 0.946 & 0.030 & 0.944 \\
\hline self \& temporary & 1.218 & 0.068 & 0.564 & 0.139 & 0.555 & 0.145 & 0.554 & 0.146 \\
\hline October 2020 (ref. March 2020) & -0.329 & 0.268 & & & & & & \\
\hline NEET*wave & -0.724 & 0.395 & & & & & & \\
\hline self \& temporary*wave & -1.009 & 0.223 & & & & & & \\
\hline $\begin{array}{l}\text { Financial condition already } \\
\text { worsen }\end{array}$ & & & 0.273 & 0.448 & & & & \\
\hline October 2020 (ref. March 2020) & & & -0.311 & 0.308 & & & & \\
\hline Worse financial condition* wave & & & -0.629 & 0.264 & & & & \\
\hline Income at risk & & & & & 0.330 & 0.347 & & \\
\hline October 2020 (ref. March 2020) & & & & & -0.389 & 0.203 & & \\
\hline Income at risk*wave & & & & & -0.176 & 0.762 & & \\
\hline Occupation at risk & & & & & & & -0.313 & 0.346 \\
\hline October 2020 (ref. March 2020) & & & & & & & -0.894 & 0.034 \\
\hline Occupation at risk*wave & & & & & & & 0.666 & 0.207 \\
\hline Constant & 0.830 & 0.012 & 0.811 & 0.019 & 0.753 & 0.034 & 1.053 & 0.004 \\
\hline \multicolumn{9}{|l|}{ Abandoning } \\
\hline \multicolumn{9}{|l|}{ Age class } \\
\hline $18-24$ & -0.235 & 0.607 & -0.318 & 0.482 & -0.248 & 0.584 & -0.315 & 0.485 \\
\hline $30-34$ & -0.140 & 0.705 & -0.314 & 0.400 & -0.231 & 0.531 & -0.236 & 0.522 \\
\hline Tertiary education & -0.287 & 0.344 & -0.186 & 0.542 & -0.233 & 0.445 & -0.238 & 0.431 \\
\hline Married/cohabiting & -0.404 & 0.228 & -0.344 & 0.300 & -0.236 & 0.484 & -0.349 & 0.289 \\
\hline With children & -0.539 & 0.147 & -0.512 & 0.162 & -0.648 & 0.081 & -0.524 & 0.151 \\
\hline High spread COVID-19 region & 0.214 & 0.487 & 0.216 & 0.483 & 0.202 & 0.512 & 0.194 & 0.525 \\
\hline
\end{tabular}


Occupational status

NEET

self \& temporary

October 2020 (ref. March 2020)

NEET*wave

self \& temporary*wave

Financial condition already

worsen

October 2020 (ref. March 2020)

Worse financial condition*wave

Income at risk

October 2020 (ref. March 2020)

Income at risk*wave

Occupation at risk

October 2020 (ref. March 2020)

Occupation at risk*wave

\begin{tabular}{|c|c|c|c|c|c|c|c|}
\hline 0.449 & 0.448 & 0.089 & 0.857 & 0.103 & 0.834 & 0.122 & 0.803 \\
\hline 2.240 & 0.001 & 1.323 & 0.001 & 1.285 & 0.002 & 1.305 & 0.001 \\
\hline-0.629 & 0.092 & & & & & & \\
\hline-0.838 & 0.429 & & & & & & \\
\hline-2.133 & 0.023 & & & & & & \\
\hline & & 0.781 & 0.044 & & & & \\
\hline & & -0.829 & 0.037 & & & & \\
\hline & & -0.610 & 0.365 & & & & \\
\hline & & & & 0.660 & 0.082 & & \\
\hline & & & & -0.948 & 0.016 & & \\
\hline & & & & 0.032 & 0.964 & & \\
\hline & & & & & & 0.089 & 0.809 \\
\hline & & & & & & -1.283 & 0.022 \\
\hline & & & & & & 0.281 & 0.677 \\
\hline 0.176 & 0.647 & 0.059 & 0.883 & 0.039 & 0.925 & 0.305 & 0.471 \\
\hline
\end{tabular}




\section{Robustness checks}

\section{Stronger and weaker retrospective fertility intentions}

Here we tested the differences in proportions (for categorical variables) and the differences in means (for continuous variables) across enlarged and restricted samples, contrasting them on our predictors and control variables.

Results from the tests show there is no differences between the two groups in terms of age, gender, proportion of those having a tertiary degree, or living in a region with high or low spread of COVID-19 cases. However, those with stronger retrospective fertility intentions are more probably married $\left(\mathrm{Pr}_{\mathrm{H} O}=0.002\right)$ with at least one child $\left(\mathrm{Pr}_{\mathrm{H} 0}=0.08\right)$, and with a "safer" occupational condition as they are more probably employees $\left(\operatorname{Pr}_{\mathrm{H} 0}=0.005\right)$, while those with weaker intentions share a higher probability of being self-employed or temporary workers $\left(\operatorname{Pr}_{\mathrm{H} 0}=0.02\right)$.

A further check has been done by performing the multinomial model on both the restricted and the enlarge samples. Results are reported in Table 8A.

Table 8A Multinomial models for the intention of still-planning, postponing or abandoning the pre-pandemic fertility plan, in the restricted and the enlarged samples (Data source: Rapporto Giovani COVID survey, March 2020 and October 2020)

\begin{tabular}{|c|c|c|c|c|}
\hline & \multicolumn{2}{|c|}{ Restricted sample } & \multicolumn{2}{|c|}{ Enlarged sample } \\
\hline & Coeff & p-value & Coeff & p-value \\
\hline \multicolumn{5}{|l|}{ Still planning } \\
\hline \multicolumn{5}{|l|}{ Postponing } \\
\hline Women & -0.128 & 0.556 & -0.187 & 0.300 \\
\hline \multicolumn{5}{|l|}{ Age class } \\
\hline $18-24$ & -0.039 & 0.909 & 0.074 & 0.788 \\
\hline $30-34$ & -0.227 & 0.386 & -0.343 & 0.106 \\
\hline Tertiary education & -0.014 & 0.949 & 0.070 & 0.702 \\
\hline Married/cohabiting & -0.696 & 0.004 & -0.608 & 0.002 \\
\hline With children & -0.380 & 0.076 & -0.214 & 0.179 \\
\hline October 2020 (ref. March 2020) & 0.454 & 0.055 & -0.452 & 0.011 \\
\hline High spread SARS-CoV-2 region & -0.580 & 0.790 & -0.001 & 0.997 \\
\hline \multicolumn{5}{|l|}{ Occupational status (ref. Employees) } \\
\hline NEET & -0.417 & 0.207 & 0.005 & 0.983 \\
\hline self \& temporary & 0.232 & 0.482 & 0.354 & 0.192 \\
\hline Constant & -0.329 & 0.489 & 1.338 & 0.000 \\
\hline
\end{tabular}




\begin{tabular}{lllll}
\hline Abandoning & & & & \\
\hline Women & 0.145 & 0.579 & 0.237 & 0.245 \\
& & & & \\
Age class & & & & \\
$18-24$ & -0.350 & 0.378 & -0.123 & 0.688 \\
$30-34$ & -0.572 & 0.055 & -0.426 & 0.068 \\
& & & & \\
Tertiary education & -0.045 & 0.868 & -0.422 & 0.049 \\
& & & & \\
Occupational status (ref. Employees) & & & & \\
NEET & 0.318 & 0.350 & 0.379 & 0.149 \\
self \& temporary & 0.600 & 0.114 & 0.877 & 0.002 \\
& & & & \\
Married/cohabiting & -0.578 & 0.042 & -0.575 & 0.009 \\
With children & -0.185 & 0.440 & -0.173 & 0.322 \\
October 2020 (ref. March 2020) & -0.211 & 0.427 & -1.047 & 0.000 \\
High spread SARS-CoV-2 region & 0.015 & 0.955 & -0.168 & 0.441 \\
& & & & \\
Constant & 0.022 & 0.967 & 1.625 & 0.000 \\
\hline
\end{tabular}

The selection into the "no plans" group

We might think that, even in January 2020 (before the occurrence of the pandemic), young people perceiving their income or occupation as vulnerable - and so independently by the crisis - were less prone to plan the arrival of a child during the next 12 months. This would imply a selection in the sample of those answering about their revised fertility plans due to the COVID-19 emergency. In this case, in fact, they would represent a less vulnerable sub-sample in terms of perspective financial consequences of the economic crisis.

To explore whether the hypothesis of as sample selection based on perceived economic and occupational vulnerability is valid, we run a set of logistic models (see Table 9A). In the Model 1 we include the occupational status, plus a set of control variables with only the socio-demographic characteristics and the residence in a region with a high diffusion of the COVID-19. In the Model 2 , Model 3 and Model 4 we add, one by one, the covariates related to the economic and occupational vulnerability: respectively, the occupation perceived as at risk, the income perceived at risk and the actual impact of the crisis on the individual's financial situation. We run separate models for women and men, to consider the possible different moderation of gender ${ }^{12}$.

12 We also performed the same analyses on the pooled sample of women and men, including interactions between the predictors and the gender dummy variable. However, results were often not enough statistically relevant to be interpreted. 
According to our selection hypothesis, the probability of being no-planners is higher when people perceive their income at risk, for both genders (Model 3) and for men also in the case in which they already experience an income loss (Model 4). However, when occupation is seen as vulnerable, this affects fertility plans more on the female than on the male side (Model 2). 
Table 9A. Logit models for those no planning to have a child in the next 12 months, by including variables on income and occupation vulnerability due to COVID-19, in 2020 (Data source: Rapporto Giovani. March October 2020).

\begin{tabular}{|c|c|c|c|c|c|c|c|c|}
\hline & \multicolumn{4}{|c|}{ Model 1} & \multicolumn{4}{|c|}{ Model 2} \\
\hline & \multicolumn{2}{|c|}{ Men } & \multicolumn{2}{|c|}{ Women } & \multicolumn{2}{|c|}{ Men } & \multicolumn{2}{|c|}{ Women } \\
\hline & $A M E$ & p-value & $A M E$ & p-value & $A M E$ & $\begin{array}{r}p- \\
\text { value }\end{array}$ & $A M E$ & $\begin{array}{c}p- \\
\text { value }\end{array}$ \\
\hline \multicolumn{9}{|l|}{ Age class } \\
\hline $25-29$ & 0.099 & 0.003 & 0.031 & 0.364 & 0.100 & 0.003 & 0.031 & 0.354 \\
\hline $30-34$ & 0.030 & 0.356 & -0.005 & 0.891 & 0.029 & 0.370 & -0.005 & 0.891 \\
\hline Tertiary education & -0.003 & 0.885 & 0.008 & 0.738 & -0.003 & 0.892 & 0.009 & 0.714 \\
\hline \multicolumn{9}{|l|}{ Occupational status } \\
\hline NEET & 0.054 & 0.102 & 0.095 & 0.000 & 0.053 & 0.106 & 0.096 & 0.000 \\
\hline self-employed \& temporary & -0.087 & 0.019 & 0.036 & 0.298 & -0.088 & 0.017 & 0.036 & 0.305 \\
\hline Married/cohabiting & -0.175 & 0.000 & -0.268 & 0.000 & -0.175 & 0.000 & -0.270 & 0.000 \\
\hline With children & -0.053 & 0.106 & 0.026 & 0.345 & -0.053 & 0.111 & 0.027 & 0.336 \\
\hline October 2020 (ref. March 2020) & 0.063 & 0.008 & 0.060 & 0.010 & 0.062 & 0.010 & 0.060 & 0.009 \\
\hline High spread COVID-19 Region & 0.055 & 0.020 & 0.065 & 0.004 & 0.055 & 0.020 & 0.066 & 0.004 \\
\hline \multirow{6}{*}{$\begin{array}{l}\text { Occupation at risk } \\
\text { Income at risk } \\
\text { Financial condition already worsen }\end{array}$} & & & & & 0.016 & 0.511 & 0.031 & 0.162 \\
\hline & & & & & & & & \\
\hline & & & & & & & & \\
\hline & \multicolumn{4}{|c|}{ Model 3} & \multicolumn{4}{|c|}{ Model 4} \\
\hline & \multicolumn{2}{|c|}{ Men } & \multicolumn{2}{|c|}{ Women } & \multicolumn{2}{|c|}{ Men } & \multicolumn{2}{|c|}{ Women } \\
\hline & $A M E$ & p-value & $A M E$ & p-value & $A M E$ & $\begin{array}{c}p- \\
\text { value }\end{array}$ & $A M E$ & $\begin{array}{c}p- \\
\text { value }\end{array}$ \\
\hline \multicolumn{9}{|l|}{ Age class } \\
\hline $25-29$ & 0.097 & 0.003 & 0.022 & 0.507 & 0.101 & 0.002 & 0.030 & 0.371 \\
\hline $30-34$ & 0.022 & 0.495 & -0.015 & 0.643 & 0.027 & 0.398 & -0.005 & 0.882 \\
\hline Tertiary education & 0.004 & 0.875 & 0.011 & 0.644 & 0.007 & 0.784 & 0.008 & 0.728 \\
\hline \multicolumn{9}{|l|}{ Occupational status } \\
\hline NEET & 0.044 & 0.191 & 0.090 & 0.000 & 0.050 & 0.130 & 0.095 & 0.000 \\
\hline self-employed \& temporary & -0.097 & 0.008 & 0.031 & 0.373 & -0.097 & 0.009 & 0.036 & 0.302 \\
\hline Married/cohabiting & -0.161 & 0.000 & -0.265 & 0.000 & -0.169 & 0.000 & -0.268 & 0.000 \\
\hline With children & -0.059 & 0.073 & 0.028 & 0.305 & -0.053 & 0.108 & 0.026 & 0.345 \\
\hline October 2020 (ref. March 2020) & 0.079 & 0.001 & 0.074 & 0.002 & 0.073 & 0.002 & 0.061 & 0.010 \\
\hline High spread COVID-19 Region & 0.053 & 0.025 & 0.063 & 0.005 & 0.058 & 0.014 & 0.065 & 0.004 \\
\hline \multicolumn{9}{|l|}{ Occupation at risk } \\
\hline Income at risk & 0.127 & 0.000 & 0.079 & 0.000 & & & & \\
\hline Financial condition already worsen & & & & & 0.095 & 0.000 & 0.005 & 0.826 \\
\hline
\end{tabular}

